\title{
Mg-Li Hybrid Batteries: The Combination of Fast Kinetics and Reduced Overpotential
}

\author{
Yajie Li, ${ }^{1,2}$ Yongjian Zheng, ${ }^{1,3,4}$ Kai Guo, ${ }^{2,5}$ Jingtai Zhao, $^{6}$ and Chilin $\mathrm{Li}^{1,3,4}$ \\ ${ }^{1}$ State Key Laboratory of High-Performance Ceramics and Superfine Microstructure, Shanghai Institute of Ceramics, \\ Chinese Academy of Sciences, Shanghai 201899, China \\ ${ }^{2}$ School of Materials Science and Engineering, Shanghai University, Shanghai 200444, China \\ ${ }^{3}$ Center of Materials Science and Optoelectronics Engineering, University of Chinese Academy of Sciences, Beijing 100049, China \\ ${ }^{4}$ CAS Key Laboratory of Materials for Energy Conversion, Shanghai Institute of Ceramics, Chinese Academy of Sciences, \\ Shanghai 201899, China \\ ${ }^{5}$ School of Physics and Materials Science, Guangzhou University, Guangzhou 510006, China \\ ${ }^{6}$ School of Materials Science and Engineering, Guilin University of Electronic Technology, Guilin 541004, China
}

Correspondence should be addressed to Chilin Li; chilinli@mail.sic.ac.cn

Received 8 June 2021; Accepted 5 August 2021; Published 4 January 2022

Copyright (C) 2022 Yajie Li et al. Exclusive Licensee Beijing Institute of Technology Press. Distributed under a Creative Commons Attribution License (CC BY 4.0).

\begin{abstract}
It is imperative for the development of cost-effective and high-performance batteries. Currently, lithium-ion batteries still occupy most of the market. However, limited lithium $(\mathrm{Li})$ resource and energy density retard their further development. The magnesium $(\mathrm{Mg})$ metal has several significant advantages; those make it a viable alternative to Li as anode, including high volume specific capacity and dendrite-free plating during cycling and high abundance. The Mg-Li hybrid batteries can combine the advantages of $\mathrm{Li}$ ion and $\mathrm{Mg}$ metal to achieve fast electrode kinetics and smooth anode deposition morphology. This review summarizes recent progresses in cathode material design and anode interface modification for Mg-Li hybrid batteries. We aim to illustrate the contribution of $\mathrm{Li}^{+}$to the electrochemical performance improvement at both cathode and anode sides and to provide inspiration for the future research in this field.
\end{abstract}

\section{Introduction}

The world energy structure is gradually shifting from fossil fuels to clean and renewable energy. Various countries also have corresponding programs, such as restricting the sales of traditional fuel vehicles and releasing green-car subsidy program to boost the application of new energy vehicles. These developments are inseparable from advanced energy storage and conversion devices. Lithium-ion batteries (LIBs) have dominated the market of portable electronic devices and electric vehicles due to the long life and stability since its launch. However, the limited Li resources and theoretical specific capacity (based on graphite anode) make LIBs unable to meet the future demand for energy storage systems. The utilization of lightweight metals (e.g., $\mathrm{Li}$ and $\mathrm{Mg}$ ) as anodes is an inevitable trend for future energy storage systems to increase energy density. The high intrinsic reactivity and instability of Li metal with air and moisture make processing and storage more difficult. The Li resources are not abundant in the earth's crust and unevenly geographically distributed, greatly leading to higher costs. In addition, there is a tendency of dendritic growth during the electrochemical deposition of Li, resulting in the dendrite penetration across separator and even a fatal short circuit of the cell. Although Mg exhibits higher redox potential $(-2.37 \mathrm{~V}$ vs. standard hydrogen electrode, SHE) than $\mathrm{Li}$ $(-3.04 \mathrm{~V}$ vs. SHE), the energy density of $\mathrm{Mg}$ metal batteries (MMBs) is compensated due to the doubled electron exchange per charge carrier. The gravimetric and volumetric capacities of $\mathrm{Mg}$ metal are as high as $2205 \mathrm{~mA} \mathrm{hg}^{-1}$ and $3833 \mathrm{~mA} \mathrm{~h} \mathrm{~cm}^{-3}$, respectively. Moreover, $\mathrm{Mg}$-based technology also has received increasing attention due to the natural abundance and low cost of $\mathrm{Mg}$ metal. More specially, $\mathrm{Mg}$ is the fifth most abundant metal in the earth's crust (cost less 
than $1 / 30$ of $\mathrm{Li}$ ) with excellent operation safety and smooth deposition morphology due to low self-diffusion barrier. Thus, MMBs are attractive candidates for large-scale energy storage systems.

It has been estimated that the volumetric energy density of $\mathrm{Mg}$ pouch cell (based on 50\% excess $\mathrm{Mg}$ metal anode and $\mathrm{Mo}_{6} \mathrm{~S}_{8}$ cathode) can reach $790 \mathrm{Wh} \mathrm{L}^{-1}$, which can exceed that of LIBs (based on graphite anode and $\mathrm{LiCoO}_{2}$ cathode), confirming the practical value of MMBs [1]. Although considering the potential advantages of MMBs in terms of cost and energy density, there are still several key factors that hinder the progress of MMBs towards application. The current challenge is twofold [2]: (1) Mg metal anode is incompatible with most electrolytes, and the electrolyte is reduced by $\mathrm{Mg}$ to form a passivation film on the anode surface that obstructs the migration of $\mathrm{Mg}^{2+}$. (2) The divalent $\mathrm{Mg}^{2+}$ has a high charge density, and a strong binding force with anions and solvents, resulting in higher energy, is needed to desolvate and overcome the high diffusion barrier. Thus, the diffusion kinetics of $\mathrm{Mg}^{2+}$ in the electrode is relatively slow, and its high polarity easily damages the cathode structure, leading to poor electrochemical behavior.

To overcome the above obstacles, more electrolyte and cathode materials have been developed. For example, in 2000, Aurbach et al. reported a long-term cycling Mg full cell coupled with a Chevrel phase $\mathrm{Mo}_{6} \mathrm{~S}_{8}$ cathode in a Grignard-based electrolyte [3]. However, the high $\mathrm{Mg}^{2+}$ migration barrier in solid state structures has not been solved. In order to design a multivalent metal battery system with a high energy density and high rate capability, in 2014, based on the classical Daniel battery model (Figure 1(a)), Yagi et al. proposed a dual-salt polyvalentmetal storage battery system (Figure 1(b)) [4]. Some candidates for anode and cathode materials in dual-salt system and the electromotive force (emf) values displayed by the corresponding combination are shown in Figure 1(c). The Mg-Li hybrid system delivers a suitable emf value and simultaneously combines the rapid diffusion of $\mathrm{Li}^{+}$in the cathode and the nondendritic deposition of $\mathrm{Mg}$ on the anode. The addition of $\mathrm{Li}^{+}$can activate the Mg-based battery system by improving the kinetics, broaden the choice of cathode materials, and also provide a new avenue for the future development of MMBs. After the proposal of a concept of Daniel-type hybrid batteries, Ichitsubo et al. then put forward a concept of "rockingchair type" hybrid batteries [5]. They used a spinel oxide $\mathrm{MgCo}_{2} \mathrm{O}_{4}$ as cathode that allows the insertion of both $\mathrm{Li}^{+}$and $\mathrm{Mg}^{2+}$. Based on a three-electrode beaker cell configuration, this concept was confirmed, though $\mathrm{Mg}$ anode is quickly passivated in the ionic liquid- (IL-) based electrolyte. Although this system is operated at $150^{\circ} \mathrm{C}$, it also provides inspiration for the design of the $\mathrm{Mg}$ - Li hybrid batteries.

In the review, the promotion effects of $\mathrm{Li}^{+}$on the cathode and anode sides in Mg-Li hybrid batteries are discussed, such as improving high-rate cycling and low temperature performance and reducing the overpotential of $\mathrm{Mg}$ deposition/dissolution. Furthermore, the electrochemical performance of some examples in $\mathrm{Mg}$ - $\mathrm{Li}$ hybrid systems is compared, and corresponding drawbacks and advantages are highlighted. We aim to illustrate the design and practicality of Mg-Li hybrid batteries and provide inspiration for further research in this field.

\section{Mg-Li Hybrid Electrolyte}

Mg-Li hybrid electrolytes are usually obtained by the addition of $\mathrm{Li}$ salt into $\mathrm{Mg}$ salt electrolyte. In this section, we will briefly introduce the formulation and corresponding electrochemical properties of several typical $\mathrm{Mg}-\mathrm{Li}$ hybrid electrolytes.

As early as 2006, Gofer et al. confirmed that $\mathrm{LiCl}$ could improve the ionic conductivity of $\mathrm{Mg}$ electrolyte solutions [6]. In 2014, Yagi et al. introduced $0.2 \mathrm{M} \mathrm{LiBF}_{4}$ into $0.5 \mathrm{M}$ all-phenyl-complex (APC) and proposed the concept of dual-salt battery ${ }^{4}$. Unfortunately, $\mathrm{BF}_{4}{ }^{-}$may react with $\mathrm{PhMgCl}$ to form $\mathrm{B}(\mathrm{Ph})_{4}{ }^{-}$, which reduces the electrochemical window of the electrolyte to $\sim 2.5 \mathrm{~V}$. So far, the most widely used $\mathrm{Mg}$-Li hybrid electrolyte is still the combination of $\mathrm{APC}$ and $\mathrm{LiCl}$. Cheng et al. added $1.0 \mathrm{M} \mathrm{LiCl}$ to $0.4 \mathrm{M}$ APC in THF to obtain an Mg-Li hybrid electrolyte [7]. In the electrolytes containing $\mathrm{LiCl}, \mathrm{Li}^{+}$intercalation is the main cathode reaction. Due to the excellent kinetics of $\mathrm{Li}^{+}$, the rate performance and cycle stability of the full cell with $\mathrm{Mo}_{6} \mathrm{~S}_{8}$ cathode have been significantly improved. Cho et al. prepared a hybrid electrolyte by adding an appropriate amount of $\mathrm{LiCl}(0.1 \mathrm{M}, 0.3 \mathrm{M}$ and $0.5 \mathrm{M})$ in the diluted $0.2 \mathrm{M} \mathrm{APC}$ solution to precisely control the insertion chemistry [8]. For the electrolytes with $\mathrm{LiCl}$ content less than or equal to $0.3 \mathrm{M}$, the cointercalation of $\mathrm{Mg}^{2+}$ into the $\mathrm{Mo}_{6} \mathrm{~S}_{8}$ cathode weakens the rate performance. When the $\mathrm{LiCl}$ concentration is increased to $0.5 \mathrm{M}$, the magnesiation can be completely suppressed and the full lithiation up to $\mathrm{Li}_{4} \mathrm{Mo}_{6} \mathrm{~S}_{8}$ can be reached. They also confirmed the relationship between the insertion chemistry at the cathode and the $\mathrm{Li}^{+}$activity in the electrolyte through calculations. As shown in Figure $1(\mathrm{~d})$, by increasing the $\mathrm{Li}^{+}$activity, the $\mathrm{Li}^{+}$insertion potential can rise above the $\mathrm{Mg}^{2+}$ insertion potential to control the intercalation chemistry at the cathode side. And due to the decrease of $\mathrm{Li}^{+}$activity in the electrolyte during the discharge, the $\mathrm{Li}^{+}$activity must be increased to 1 in order to completely suppress $\mathrm{Mg}^{2+}$ insertion.

For $\mathrm{Mg}\left(\mathrm{BH}_{4}\right)_{2}$-based electrolyte, it has been demonstrated that $\mathrm{LiBH}_{4}$ addition can improve the coulombic efficiency (CE) [9]. Shao et al. further explored the influence of the concentration of $\mathrm{LiBH}_{4}$ and different solvent on the performance in the case of $0.1 \mathrm{MMg}\left(\mathrm{BH}_{4}\right)_{2}$ electrolyte [10]. Taking the diglyme (DGM) solvent as an example, as the concentration of $\mathrm{LiBH}_{4}$ increases, the kinetics of $\mathrm{Mg}$ plating/stripping is significantly enhanced due to the synergistic effect of chelating solvent and increased $\mathrm{BH}_{4}{ }^{-}$concentration. When the $\mathrm{LiBH}_{4}$ concentration is $1.5 \mathrm{M}$, the current density reaches the maximum.

Cheng et al. investigated the regulation of Li salt on electrolyte chemistry [11]. They chose a series of Li salts of $\mathrm{LiAlCl}_{4}, \mathrm{LiTFSI}, \mathrm{LiCl}$, and $\mathrm{LiPF}_{6}$ to add into $0.2 \mathrm{M}$ $\left[\mathrm{Mg}_{2} \mathrm{Cl}_{2}(\mathrm{DME})_{4}\right]\left[\mathrm{AlCl}_{4}\right]_{2}$ electrolyte to obtain dual-salt electrolytes with a targeted $\mathrm{Li}^{+}$concentration of $0.4 \mathrm{M}$. $\mathrm{LiCl}$ and 


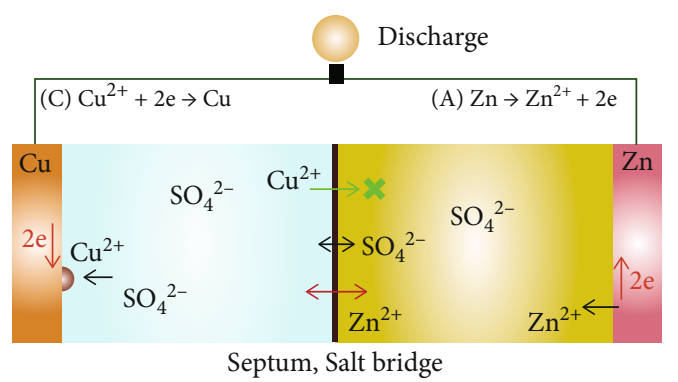

(a)

Virtual Li pass filter: $\mathrm{Li}^{+}$ions are inserted preferentially

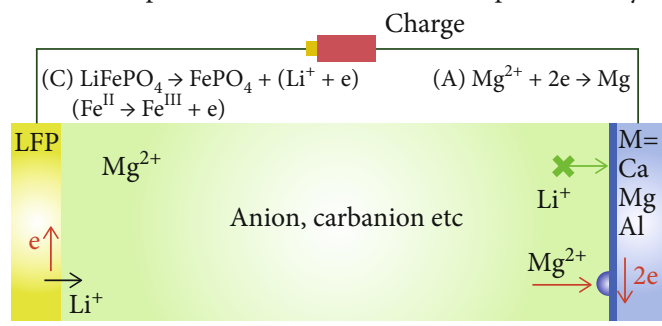

Virtual Mg filter: Mg is electrodeposited preferentially

(b)

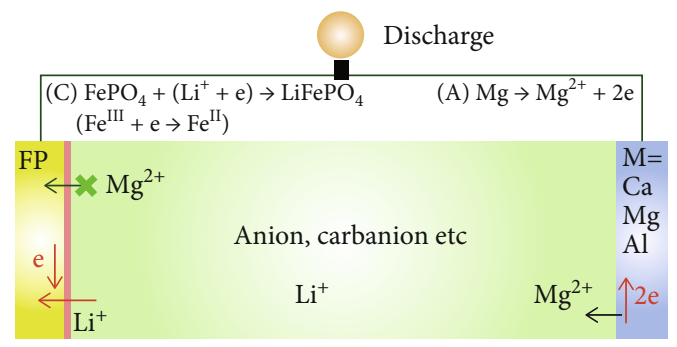

Negative-electrode metal candidate

\begin{tabular}{ccccc}
$-3.05 \mathrm{~V}$ & $-2.87 \mathrm{~V}$ & $-2.36 \mathrm{~V}$ & \multicolumn{2}{c}{$-1.66 \mathrm{~V}$} \\
$\mathrm{Li}$ & $\mathrm{Ca}$ & $\mathrm{Mg}$ & $\mathrm{Al}$ & Light metal \\
$-3 \mathrm{~V}$ & & $-2 \mathrm{~V}$ & & $-1 \mathrm{~V}$
\end{tabular}

Less-noble

Electrode potential vs. SHE

Noble

Positive-electrode candidate

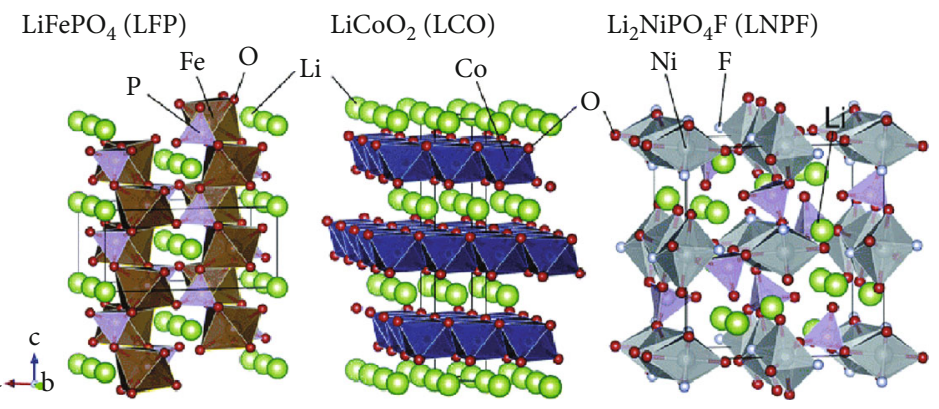

Emf expected for various combinations of above materials

\begin{tabular}{llll} 
& $\mathrm{LiFePO}_{4}$ & $\mathrm{LiCoO}_{2}$ & $\mathrm{Li}_{2} \mathrm{NiPO}_{4} \mathrm{~F}$ \\
\hline $\mathrm{Li} / \mathrm{Li}^{+}$ & $3.4 \mathrm{~V}$ & $4.2 \mathrm{~V}$ & $4.5 \sim 5 \mathrm{~V}$ \\
\hline $\mathrm{Ca} / \mathrm{Ca}^{2+}$ & $3.2 \mathrm{~V}$ & $4.0 \mathrm{~V}$ & $4.3 \sim 4.8 \mathrm{~V}$ \\
$\mathrm{Mg} / \mathrm{Mg}^{2+}$ & $2.7 \mathrm{~V}$ & $3.5 \mathrm{~V}$ & $3.8 \sim 4.3 \mathrm{~V}$ \\
$\mathrm{Al} / \mathrm{Al}^{3+}$ & $2.0 \mathrm{~V}$ & $2.8 \mathrm{~V}$ & $3.1 \sim 3.6 \mathrm{~V}$ \\
\hline
\end{tabular}

(c)

Increasing $\mathrm{Li}^{+}$activity, $\mathrm{a}_{\mathrm{Li}+}$
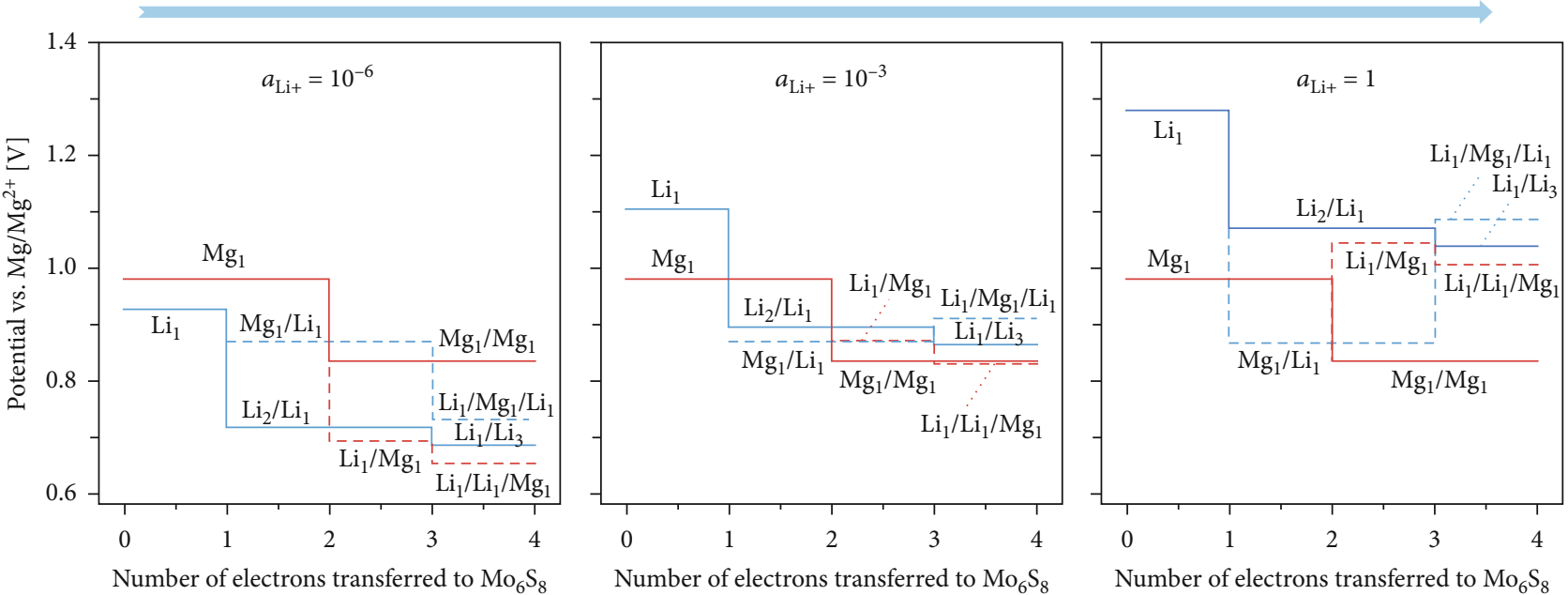

(d)

Figure 1: (a) Schematic illustration of classical Daniel battery. (b) Schematic illustration of septum-free dual-salt polyvalent-metal storage battery (PSB) model based on Daniel battery. (c) Examples of negative and positive electrode materials for the proposed PSBs [4]. (d) Lithiation and magnesiation potentials of $\mathrm{Mo}_{6} \mathrm{~S}_{8}\left(\mathrm{vs} . \mathrm{Mg} / \mathrm{Mg}^{2+}\right)$ at different $\mathrm{Li}^{+}$activities $\left(\mathrm{a}_{\mathrm{Li}}{ }^{+}\right)$[8].

$\mathrm{LiPF}_{6}$ cannot be completely dissolved, while LiTFSI exhibits superior solubility up to $2 \mathrm{M}$. Adopting $0.4 \mathrm{M} \mathrm{LiAlCl}_{4}$ enhanced $\mathrm{Mg}$ electrolyte and $\mathrm{LiFePO}_{4}$ or $\mathrm{LiMn}_{2} \mathrm{O}_{4}$ cathode loaded on Mo current collector enables the design of high voltage Mg-Li hybrid batteries.
In addition, LiTFSI was also often used as a Li source for other dual-salt electrolytes, especially in combination with nonnucleophilic $\mathrm{Mg}$ electrolytes, such as magnesiumbis(hexamethyldisilazide) (Mg-HMDS) [12]. There are also the combinations of $\mathrm{MgCF}_{3} \mathrm{SO}_{3}+\mathrm{LiCF}_{3} \mathrm{SO}_{3}$ as well as 
magnesium aluminate chloride complex $(\mathrm{MACC})+\mathrm{LiCl}$ for the Mg-S systems [13, 14].

\section{Influence of $\mathrm{Li}^{+}$on Cathode in $\mathrm{Mg}-\mathrm{Li}$ Hybrid Systems}

Although the radii of $\mathrm{Mg}^{2+}$ and $\mathrm{Li}^{+}$are not much different, $\mathrm{Mg}$ ions are given slow kinetics of insertion into inorganic hosts due to the divalent character. Therefore, using $\mathrm{Li}^{+}$ instead of $\mathrm{Mg}^{2+}$ to insert into the cathode host can increase the current density of battery operation and improve rate performance. In addition, the introduction of $\mathrm{Li}^{+}$can mitigate the size dependency of electrochemical kinetics, whereas a faster and more effective intercalation of $\mathrm{Mg}^{2+}$ was observed in the same material with nanosized particles than micron-sized particles. Next, we will introduce some examples of the improvement of cathode materials in the $\mathrm{Mg}$-Li hybrid system, especially the reaction mechanism and the improvement of rate performance.

3.1. Enhanced Rate Performance and Cycle Stability. Similar to LIBs, the intercalation is also one of the important chargestorage mechanisms in the $\mathrm{Mg}-\mathrm{Li}$ hybrid system. The research on intercalation-type materials in $\mathrm{Mg}$ - $\mathrm{Li}$ hybrid tends to embrace classical Chevrel phase $\mathrm{Mo}_{6} \mathrm{X}_{8}(\mathrm{X}=\mathrm{S}$, Se, or their combination), layered structures like typical $\mathrm{TiS}_{2}$, $\mathrm{TiO}_{2}$, and $\mathrm{V}_{2} \mathrm{O}_{5}$, and intercalation compounds which have been proven to be suitable electrode materials in Li battery systems, such as $\mathrm{LiFePO}_{4}$. There is almost no obvious structural change in the appropriate amount of $\mathrm{Li}^{+}$or $\mathrm{Mg}^{2+}$ intercalation/de-intercalation except inevitable volume expansion. The structural peculiarities of intercalation-type cathodes contribute to the highly reversible storage process and superior cycling stability.

Chevrel phase $\mathrm{Mo}_{6} \mathrm{~S}_{8}$ as a classic cathode material for rechargeable $\mathrm{Mg}$ batteries has received widespread attention once it came out. For Mg-Li hybrid batteries, the intercalation mechanism of $\mathrm{Mo}_{6} \mathrm{~S}_{8}$ has also been deeply investigated by several research groups. In the previous section, the influence of $\mathrm{Li}^{+}$concentration in the APC electrolyte on the selectivity of $\mathrm{Mo}_{6} \mathrm{~S}_{8}$ to lithiation or magnesiation has been introduced. Cheng et al. combined the advantages of $\mathrm{Mg}$ anode and dual-salt electrolyte to obtain the outstanding rate performance of $\mathrm{Mo}_{6} \mathrm{~S}_{8}\left(105 \mathrm{mAhg}^{-1}\right.$ at 15 C) [7]. For $\mathrm{Mg}\left(\mathrm{BH}_{4}\right)_{2}-\mathrm{LiBH}_{4}-\mathrm{DGM}$ electrolyte, Shao et al. reported that an initial capacity of $99.5 \mathrm{~mA} \mathrm{~h} \mathrm{~g}^{-1}$ at C/10 rate with a $89.7 \%$ capacity retention for 300 cycles is governed by reversible $\mathrm{Mg}^{2+}$ insertion/deinsertion on $\mathrm{Mo}_{6} \mathrm{~S}_{8}$ [10]. For the $0.1 \mathrm{M}$ $\mathrm{Mg}\left(\mathrm{BH}_{4}\right)_{2}$ system with different solvents, the addition of $\mathrm{LiBH}_{4}$ shows an increase in CE. And as the concentration of $\mathrm{LiBH}_{4}$ increases, the $\mathrm{CE}$ value of the corresponding electrolyte also increases. The effect of $\mathrm{LiBH}_{4}$ on electrochemical performance seems to be focused on changing $\mathrm{Mg}$ electrochemistry by $\mathrm{BH}_{4}^{-}$rather than $\mathrm{Li}^{+}$to promote the $\mathrm{Mg}$ deposition/dissolution. The unique solvation structures endow the $\mathrm{Mg}\left(\mathrm{BH}_{4}\right)_{2}$ electrolyte with the differentiated $\mathrm{CE}$ values in different solvents. Compared with THF and DME solvents, DGM is both thermodynamically and kinetically favorable in the $\mathrm{Mg}$ stripping process. $\mathrm{BH}_{4}{ }^{-}$acts as the sec- ond coordination, and the increased concentration of $\mathrm{BH}_{4}{ }^{-}$ accelerates the $\mathrm{Mg}$ stripping by prompting the formation of coordination structures (e.g., $\mathrm{Mg}\left(\mathrm{BH}_{4}\right)_{2} \mathrm{DGM}$, $\mathrm{Mg}_{2}\left(\mathrm{BH}_{4}\right)_{4}(\mathrm{DME})_{3}$, and $\left.\mathrm{Mg}\left(\mathrm{BH}_{4}\right)_{2}(\mathrm{THF})_{3}\right)$.

Layered $\mathrm{MoS}_{2}$ is considered an attractive host for ion intercalation due to weak van der Waals' interaction between layers and the large interlayer distance. Hsu et al. demonstrated that commercial micron-scale $\mathrm{MoS}_{2}$ could accommodate both $\mathrm{Mg}^{2+}$ and $\mathrm{Li}^{+}$after the phase transition induced by $\mathrm{Li}^{+}$-intercalation [15]. A plateau at $0.2 \mathrm{~V}$ in the first discharge is observed, corresponding to the phase transition from $2 \mathrm{H}-\mathrm{MoS}_{2}$ to $1 \mathrm{~T}-\mathrm{MoS}_{2}$ [16]. In the subsequent cycles, a reversible capacity is $160 \mathrm{~mA} \mathrm{hg}^{-1}$ at $25 \mathrm{mAg}^{-1}$. They also constructed an effective electronic conducting network by ball-milling $\mathrm{MoS}_{2}$ with carbon nanotubes (CNT) or graphene nanosheets. Due to the improved charge transfer ability, the $\mathrm{MoS}_{2} / \mathrm{CNT}$ and $\mathrm{MoS}_{2}$ /graphene composite cathodes deliver the discharge capacities of $\sim 200 \mathrm{mAh} \mathrm{g}^{-1}$ and $225 \mathrm{~mA} \mathrm{~h} \mathrm{~g}^{-1}$, respectively. By constructing a sufficient electronic wiring network and hierarchical conductive structure, the performance of the cathode materials can be further improved. Hou et al. designed a hollow opening nanoflower (HONF) $\mathrm{MoS}_{2}$-CuS-EG electrode by a facile hydrothermal method [17], combining the high-conductivity $\mathrm{CuS}$ and expanded graphite (EG) with large pores. CuS facilitates electron transport and contributes to a small amount of capacity (9.46\%). EG can alleviate volume expansion and improve cycle stability. And $\mathrm{MoS}_{2}$ nanosheets with enlarged layer spacing make $\mathrm{Li}^{+}$intercalation easier.

Layered $\mathrm{TiS}_{2}$ is also identified as a possible candidate for $\mathrm{Mg}-\mathrm{Li}$ hybrid batteries because of its high capacity $\left(240 \mathrm{~mA} \mathrm{hg}^{-1}\right)$ and suitable voltage $(1.0 \sim 1.6 \mathrm{~V}$ vs. $\left.\mathrm{Mg} / \mathrm{Mg}^{2+}\right)$. Gao et al. studied the commercial micron-sized $\mathrm{TiS}_{2}$ as cathode in Mg-Li hybrid batteries [18]. They found that there is only $\mathrm{Li}^{+}$intercalation into micron-sized $\mathrm{TiS}_{2}$ in the dual-salt electrolyte. Owing to the superior reversibility of $\mathrm{TiS}_{2}$, a specific capacity of $161 \mathrm{mAhg}^{-1}$ with a CE value as high as $99.5 \%$ is observed for at least 400 cycles with no capacity fade at $\mathrm{C} / 3$ rate. As shown in Figure 2(a), Yoo et al. also demonstrated that the performance of $\mathrm{TiS}_{2}$ in $\mathrm{Mg}$-Li hybrid batteries is better than that in Li metal batteries (LMBs) with high active material loading $(8.0 \pm 0.5$ $\left.\mathrm{mg} \mathrm{cm}{ }^{-2}\right)$ at $1 \mathrm{C}\left(=2 \mathrm{~mA} \mathrm{~cm}^{-2}\right)$ [19]. Due to the formation of Li dendrite, the reference Li battery suffers the fast capacity decay. The cross-sectional SEM image of $\mathrm{Mg}$ anode in Figure 2(b) shows the single-layer polyhedral Mg deposits with an average size of $\sim 100 \mu \mathrm{m}$. Benefitting from the dendrite-free deposition of $\mathrm{Mg}$ anode, $\mathrm{Mg}$-Li hybrid batteries have been confirmed to be new opportunities for their application in large-scale energy storage under practical high current and high areal capacity conditions.

Similarly, other layered sulfides can also be applied in the $\mathrm{Mg}$-Li hybrid system. Sun et al. reported the performance of $\mathrm{VS}_{2}$ nanosheet cathode in Mg-Li hybrid batteries [20]. $\mathrm{VS}_{2}$ has a layered structure with a layer spacing of $5.76 \AA$, composed of a metal vanadium layer between two sulfide layers to form a sandwich S-V-S structure. In a hybrid system, $\mathrm{Li}^{+}$intercalation/deintercalation is dominant at the cathode side during the electrochemical process. They also made 


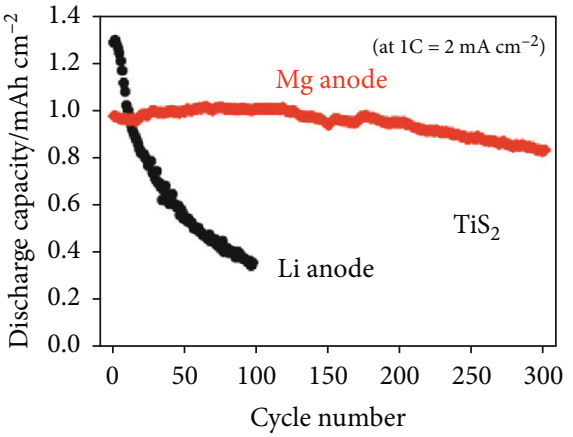

(a)

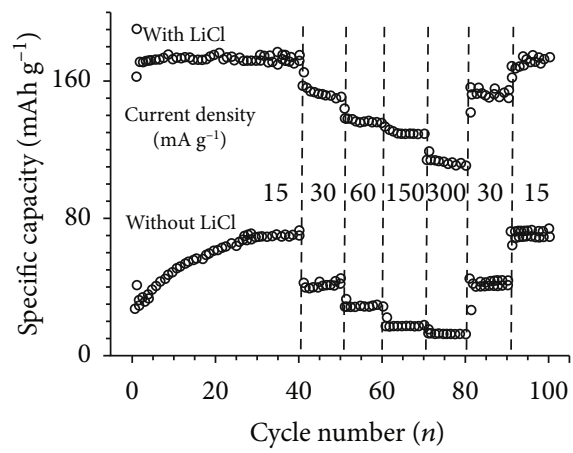

(d)

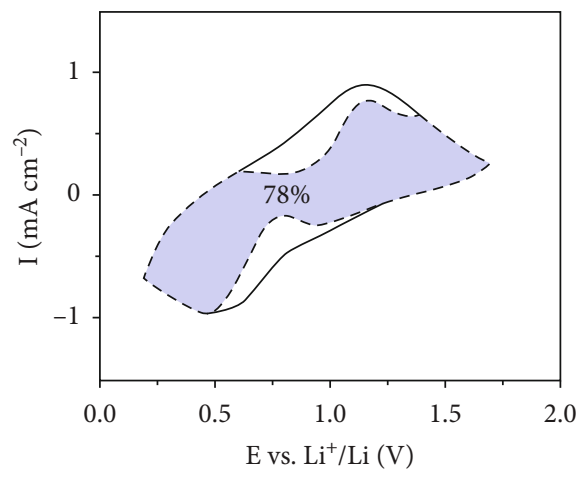

(g)

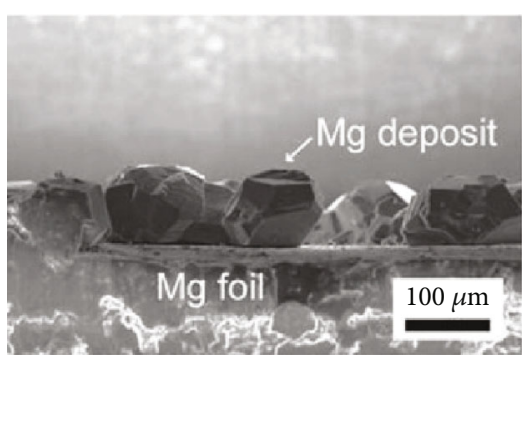

(b)

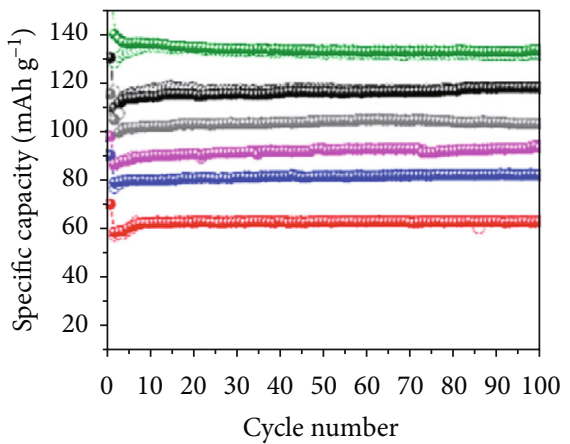

$$
\begin{aligned}
& \rightarrow 25^{\circ} \mathrm{C} \quad \rightarrow-30^{\circ} \mathrm{C} \\
& \rightarrow-20^{\circ} \mathrm{C} \quad \rightarrow-10^{\circ} \mathrm{C} \\
& \rightarrow 0^{\circ} \mathrm{C} \quad \rightarrow-40^{\circ} \mathrm{C}
\end{aligned}
$$

(e)

$\mathrm{TiNb}_{2} \mathrm{O}_{7}$ in Li- vs. hybrid $\mathrm{Mg}$-Li cell at $60^{\circ} \mathrm{C}$

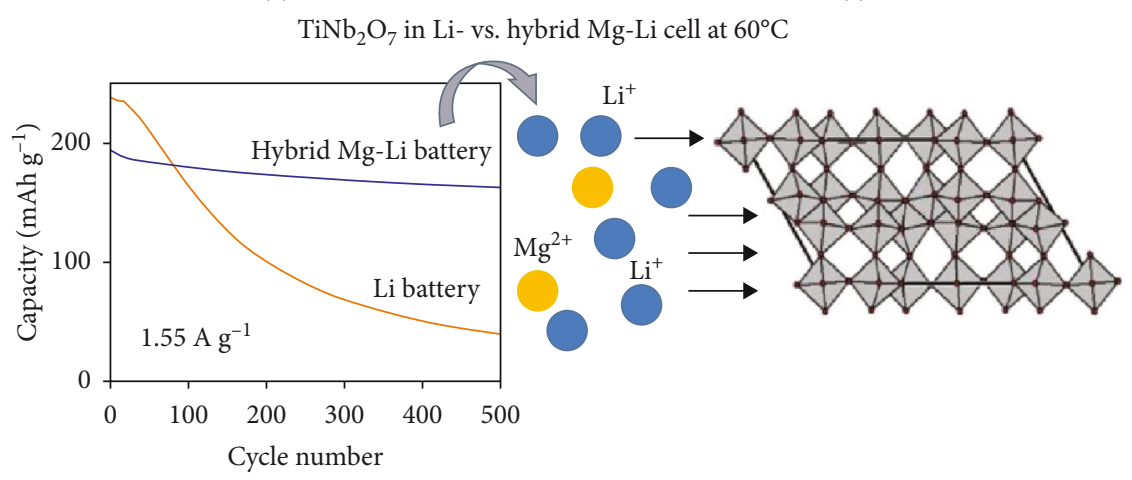

(h)

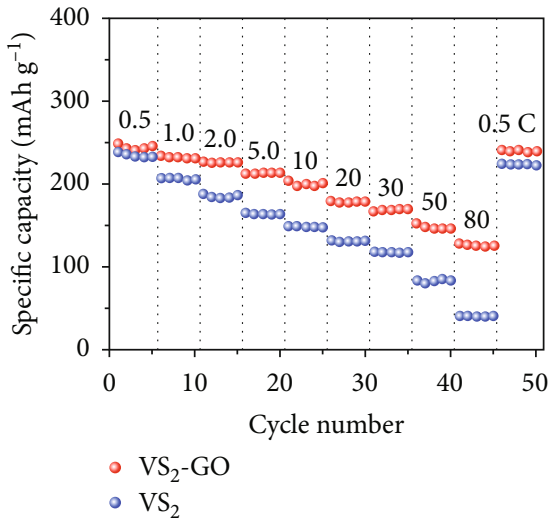

(c)

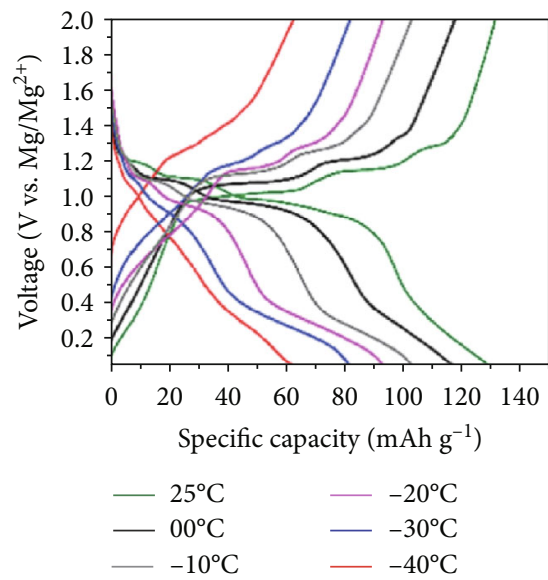

(f)

FIgure 2: (a) Comparison of discharge capacities as a function of cycle number between Li-anode cell and Mg-metal hybrid cell. (b) Crosssectional SEM image of Mg metal anode after plating [19]. (c) Rate performance comparison between $\mathrm{VS}_{2}-\mathrm{GO}$ and $\mathrm{VS}_{2}$. (1 C $=180 \mathrm{~mA} \mathrm{~g}{ }^{-1}$ ) [20]. (d) Comparison of rate capabilities of LTO electrodes in the electrolytes with and without LiCl [26]. (e) Cycle performance and (f) corresponding charge-discharge curves of LVP || $\mathrm{APC}-\mathrm{LiCl}|| \mathrm{Mg}$ cells at room and lower temperatures $(0,-10,-20,-30$, and-40 $\mathrm{C})$ at $100 \mathrm{~mA} \mathrm{~g}^{-1}$ [42]. (g) Cyclic voltammogram curve of $\mathrm{TiNb}_{2} \mathrm{O}_{7}$ in hybrid $\mathrm{Mg}$-Li batteries at room temperature at $0.1 \mathrm{mV} \mathrm{s}{ }^{-1}$; the colored area represents capacitive charge contribution [46]. (h) Discharge capacity of $\mathrm{TNb}_{2} \mathrm{O}_{7}$ in $\mathrm{Li}$ and hybrid $\mathrm{Mg}$-Li batteries at $20 \mathrm{C}$ $\left(1550 \mathrm{~mA} \mathrm{~g}^{-1}\right)$ at $60^{\circ} \mathrm{C}$, together with schematic diagram of $\mathrm{Li}^{+}$intercalation [47].

the further improvement by wrapping $\mathrm{VS}_{2}$ with graphene $\left(\mathrm{VS}_{2}-\mathrm{GO}\right)$ to construct a conductive network. The $\mathrm{VS}_{2}-\mathrm{GO}$ cathode exhibits an outstanding high-rate capacity of $129 \mathrm{~mA} \mathrm{~h} \mathrm{~g}^{-1}$ at $80 \mathrm{C}\left(1 \mathrm{C}=180 \mathrm{~mA} \mathrm{~g}^{-1}\right.$, Figure 2(c)) and long life $\left(146 \mathrm{~mA} \mathrm{~h} \mathrm{~g}^{-1}\right.$ after 10000 cycles at $\left.5 \mathrm{C}\right)$. And it is estimated that the energy density of this hybrid system can reach up to $353 \mathrm{Wh} \mathrm{kg}^{-1}$. The crystal structure of $\mathrm{VS}_{4}$ con- sists of $\mathrm{V}^{4+}$ ions coordinated to sulfur dimers $\left(\mathrm{S}_{2}{ }^{2-}\right)$ extending along the $\mathrm{c}$ axis, and the distance between atomic chains is $5.83 \AA$. And $\mathrm{VS}_{4}$ has been demonstrated to have the ability to allow $\mathrm{Mg}^{2+}$ diffusion and storage due to linear open channels and sufficient $\mathrm{S}_{2}{ }^{2-}$ active sites [21]. Wang et al. reported $\mathrm{VS}_{4}$ nanodendrites as cathode for $\mathrm{Mg}$ - Li hybrid batteries [22]. Not only it is observed that $\mathrm{Mg}^{2+} / \mathrm{Li}^{+}$cointercalation 
occurs on the cathode side, but also the inductively coupled plasma optical emission spectrometer (ICP-OES) and electrochemical results indicate that the capacity contribution of $\mathrm{Mg}^{2+}$ storage is much higher than that of $\mathrm{Li}^{+}$, which is different from other $\mathrm{Mg}^{2+} / \mathrm{Li}^{+}$cointercalation cathode materials. Although $\mathrm{Li}^{+}$contributes little to the capacity, $\mathrm{Li}^{+}$ significantly accelerates the reaction kinetics; thus, the activation process is not observed during the initial cycles in the Mg-Li hybrid system. Benefitting from fast kinetics, the $\mathrm{VS}_{4}$ cathode delivers a high reversible capacity of $\sim 300 \mathrm{~mA} \mathrm{~h} \mathrm{~g}^{-1}$ at $100 \mathrm{~mA} \mathrm{~g}^{-1}$ and long-term cycling stability $\left(110 \mathrm{~mA} \mathrm{~h} \mathrm{~g}^{-1}\right.$ after 1500 cycles at $1000 \mathrm{~mA} \mathrm{~g}^{-1}$ ).

Titanium-based materials have been reported as a class of alternative materials for anode of LIBs [23], such as $\mathrm{TiO}_{2}$ and $\mathrm{Li}_{4} \mathrm{Ti}_{5} \mathrm{O}_{12}$ (LTO). Su et al. reported a Mg-Li hybrid battery with a $\mathrm{Mg}$ anode, a commercial anatase $\mathrm{TiO}_{2}$ as cath-

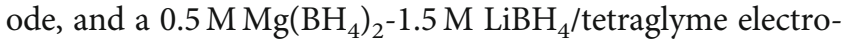
lyte [24]. They obtained an initial discharge capacity of $155.8 \mathrm{~mA} \mathrm{hg}^{-1}$, which decreases to $\sim 140 \mathrm{~mA} \mathrm{~h}^{-1}$ after 90 cycles at a rate of $0.2 \mathrm{C}\left(1 \mathrm{C}=168 \mathrm{~mA} \mathrm{~g}^{-1}\right)$. Spinel LTO is considered a "zero-strain" material for $\mathrm{Li}$ and $\mathrm{Mg}$ insertion with only $0.2 \%$ and $0.8 \%$ change in the lattice constant, respectively $[23,25]$. Wu et al. confirmed the cointercalation of $\mathrm{Mg}^{2+}$ and $\mathrm{Li}^{+}$into LTO through DFT calculations and experiments [26]. For the LTO nanoparticle (>100 nm) electrode, there is the existence of a threshold $\mathrm{Li}^{+}$activity. Using the optimized $0.25 \mathrm{M}$ APC- $0.25 \mathrm{M} \mathrm{LiCl}$ electrolyte, they obtained a reversible capacity of $\sim 175 \mathrm{mAhg}^{-1}$, where the intercalation of $\mathrm{Mg}^{2+}$ contributes more than $90 \mathrm{~mA} \mathrm{~h}^{-1}$. As shown in Figure 2(d), the introduction of $\mathrm{Li}^{+}$not only avoids the initial activation process but also improves the rate performance to $120 \mathrm{~mA} \mathrm{~h} \mathrm{~g}^{-1}$ at $300 \mathrm{mAg}^{-1}$. Miao et al. reported the $\mathrm{Mg}$-Li hybrid batteries based on commercial LTO cathode

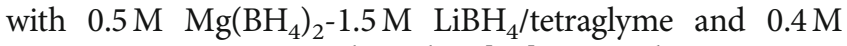
APC-1.5 $\mathrm{M} \mathrm{LiBH}_{4} / \mathrm{THF}$ electrolyte [27]. Due to lower overpotential and higher CE, the APC-based electrolyte system shows the better cycling performance. In addition, the $\mathrm{Mg}$ storage behavior of LTO cathode has a size dependence effect, resulting in negligible $\mathrm{Mg}^{2+}$ intercalation into commercial LTO used in this study. The conductivity of LTO can be further improved by doping at the $\mathrm{Ti}^{4+}$ sites with $\mathrm{Fe}^{3+}, \mathrm{Ni}^{3+}, \mathrm{Al}^{3+}$, or $\mathrm{Cr}^{3+}$. Yao et al. evaluated $\mathrm{LiCrTiO}_{4}$ spinel as cathode for $\mathrm{Mg}$-Li hybrid batteries [28]. Only $\mathrm{Li}^{+}$intercalation into the high-temperature synthesized $\mathrm{LiCrTiO}_{4}$ is observed. $\mathrm{LiCrTiO}_{4}$ exhibits a reversible capacity of $\sim 170 \mathrm{~mA} \mathrm{~h} \mathrm{~g}^{-1}$ at $20 \mathrm{mAg}^{-1}$ in $0.3 \mathrm{M}$ APC-1 M LiCl. Due to the lower operating voltage, titanium-based materials may not meet the demand for high-energy-density Mg-Li hybrid batteries.

Manganese oxides are reported as electrode materials with various structures, such as tunnel-type $\alpha-\mathrm{MnO}_{2}$ (e.g., hollandite with a $2 \times 2$ tunnel and todorkite with a $3 \times 3$ tunnel), layered birnessite-type $\mathrm{MnO}_{2}$ and spinel $\mathrm{MnO}_{2}$. For MMBs, $\mathrm{MnO}_{2}$ cathode materials suffer poor capacity retention due to irreversible phase transition. Asif et al. prepared birnessite-type Ni-doped $\mathrm{MnO}_{2}$ nanoflakes on CNT to improve electrochemical performance [29]. The optimized cathode delivers a maximum specific capacity of $175 \mathrm{~mA} \mathrm{~h} \mathrm{~g}^{-1}$ at $20 \mathrm{mAg}^{-1}$. Together with limited high-rate capacity $\left(\sim 60 \mathrm{~mA} \mathrm{~h} \mathrm{~g}^{-1}\right.$ at $\left.1 \mathrm{~A} \mathrm{~g}^{-1}\right)$ and low voltage plateaus, the predescribed cathodes are not a suitable choice for $\mathrm{Mg}-\mathrm{Li}$ hybrid batteries. Then, Asif et al. prepared a ternary transition metal oxide $(\mathrm{NiMnCo})_{3} \mathrm{O}_{4}$ with the morphology of multishelled hollow spheres by a hydrothermal method and thermal treatment [30]. The (NiMnCo) ${ }_{3} \mathrm{O}_{4}$ cathode exhibits an extraordinary reversible capacity of $550 \mathrm{~mA} \mathrm{~h} \mathrm{~g}^{-1}$ at $50 \mathrm{mAg}^{-1}$ as well as a remarkable energy density (368 $\mathrm{Wh} \mathrm{kg}^{-1}$ ) and cycle life $\left(277 \mathrm{~mA} \mathrm{~h} \mathrm{~g}^{-1}\right.$ after 100 cycles) at $100 \mathrm{~mA} \mathrm{~g}^{-1}$. Although the magnesiation/demagnesiation process is observed in APC electrolyte, the following $\mathrm{Li}^{+}$ insertion reaction still dominates in the hybrid electrolyte: $x \mathrm{Li}^{+}+x \mathrm{e}^{-}(\mathrm{NiMnCo})_{3} \mathrm{O}_{4} \longrightarrow \mathrm{Li}_{x}(\mathrm{NiMnCo})_{3} \mathrm{O}_{4}$. Lithium manganese oxide with a high discharge voltage platform $\left(>2.0 \mathrm{~V}\right.$ vs. $\left.\mathrm{Mg} / \mathrm{Mg}^{2+}\right)$ is a family of promising cathode for high energy density $\mathrm{Mg}$-Li hybrid batteries. Pan et al. investigated the electrochemical behavior of $\mathrm{LiMn}_{2} \mathrm{O}_{4}$ in two chloride-free hybrid electrolytes, namely, $\mathrm{Mg}$ (TFSI)2-LiTFSI and $\mathrm{Mg}(\mathrm{CB} 11 \mathrm{H} 12) 2-\mathrm{LiTFSI}$ [31]. $\mathrm{LiMn}_{2} \mathrm{O}_{4}$ exhibits an initial capacity of $106 \mathrm{mAhg}^{-1}$ with a working voltage of $\sim 2.8 \mathrm{~V}$, corresponding to $\mathrm{Li}^{+}$intercalation. However, the capacity fading in Mg-Li hybrid system is fast, and further optimization is needed. It is reported the $\mathrm{Mn}^{3+}$ suffers Jahn-Teller distortion and disproportionation reaction $\left(\mathrm{Mn}^{3+} \longrightarrow \mathrm{Mn}^{2+}+\mathrm{Mn}^{4+}\right)$, resulting in the structural collapse. Li-rich $\mathrm{Li}_{4} \mathrm{Mn}_{5} \mathrm{O}_{12}$ with stable $\mathrm{Mn}^{4+}$ provides a theoretical capacity of $163 \mathrm{~mA} \mathrm{hg}^{-1}$. Cen et al. synthesized spinel $\mathrm{Li}_{4} \mathrm{Mn}_{5} \mathrm{O}_{12}$ nano/microspheres via a hydrothermal and lower temperature sintering method and investigated its performance for $\mathrm{Mg}$-Li hybrid batteries [32]. Due to the smaller lattice constant of $\mathrm{Li}_{4} \mathrm{Mn}_{5} \mathrm{O}_{12}$, it is more difficult for $\mathrm{Mg}^{2+}$ or solvated $\mathrm{MgCl}^{+}$to diffuse in host, so only $\mathrm{Li}^{+}$ intercalation occurs at the cathode side. Benefiting from nano/microhierarchical architecture and open $3 \mathrm{D} \mathrm{Li}^{+}$channels, the $\mathrm{Li}_{4} \mathrm{Mn}_{5} \mathrm{O}_{12}$ cathode exhibits a reversible capacity of $155 \mathrm{~mA} \mathrm{~h}^{-1}$ at $0.1 \mathrm{C}$ and the corresponding $\mathrm{Mg}$-Li hybrid system has a high energy density of $326 \mathrm{Wh} \mathrm{kg}^{-1}$.

Vanadium dioxide $\left(\mathrm{VO}_{2}\right)$ can offer a relatively high operating voltage $\left(\sim 2.5 \mathrm{~V}\right.$ vs. $\mathrm{Li} / \mathrm{Li}^{+}, \sim 1.75 \mathrm{~V}$ vs. $\left.\mathrm{Mg} / \mathrm{Mg}^{2+}\right)$ in the Mg-Li hybrid system to increase energy density. Pei et al. synthesized $\mathrm{VO}_{2}$ nanoflakes through a hydrothermal method and investigated its performance in $\mathrm{Mg}$-Li hybrid batteries [33]. It should be noted that since excessive $\mathrm{Li}^{+}$ insertion damages the $\mathrm{VO}_{2}$ structure, a suitable voltage window $(0.5-2.0 \mathrm{~V})$ could improve the cycle stability, and it corresponds to the discharge product of $\mathrm{Li}_{x} \mathrm{VO}_{2}(x=0.78)$. The $\mathrm{VO}_{2}$ nanoflakes exhibit a high discharge capacity of $206.8 \mathrm{~mA} \mathrm{~h} \mathrm{~g}^{-1}$ and a capacity retention of $75 \%$ (after 100 cycles) at $100 \mathrm{mAg}^{-1}$. Vanadium pentoxide $\left(\mathrm{V}_{2} \mathrm{O}_{5}\right)$ has abundant reserves and unique electrochemical storage properties. With different amounts of $\mathrm{Li}^{+}$inserted, $\mathrm{V}_{2} \mathrm{O}_{5}$ shows different capacity retentions due to the reversible or irreversible phase formation [34]. Yoo et al. observed one equivalent $\mathrm{Li}^{+}$insertion into $\mathrm{V}_{2} \mathrm{O}_{5}$ in $0.25 \mathrm{M} \mathrm{APC}-0.25 \mathrm{M} \mathrm{LiCl} \mathrm{[35].}$ And it has been confirmed that $\mathrm{V}_{2} \mathrm{O}_{5}$ and $\mathrm{MoO}_{3}$ allow a reversible $\mathrm{Mg}$-ion intercalation. Based on this, Miao et al. reported layered vanadium-molybdenum-oxides $\mathrm{V}_{2} \mathrm{MoO}_{8}$ (VMO) with a high theoretical capacity of $493 \mathrm{~mA} \mathrm{hg}^{-1}$ as cathode in $\mathrm{Mg}$-Li hybrid batteries [36]. According to the result by ICP, after the first discharging, the cathode 
becomes $\mathrm{Mg}_{0.7} \mathrm{Li}_{2.39} \mathrm{~V}_{2} \mathrm{MoO}_{8}$, but the insertion of $\mathrm{Li}^{+}$and $\mathrm{Mg}^{2+}$ into the VMO structure is partially irreversible, resulting in a relatively low initial CE (87.15\%). Although the initial discharge capacity is up to $312 \mathrm{~mA} \mathrm{~h} \mathrm{~g}^{-1}$ at $20 \mathrm{~mA} \mathrm{~g}^{-1}$, the relatively poor retention is worrying. The $\mathrm{Mg}-\mathrm{Li}$ hybrid electrolyte also can boost up the capacity of $\mathrm{NaV}_{3} \mathrm{O}_{8} \cdot 1.69$ $\mathrm{H}_{2} \mathrm{O}$ from $110 \mathrm{~mA} \mathrm{hg}^{-1}$ (at $10 \mathrm{mAg}^{-1}$ for pure $\mathrm{Mg}$ electrolyte system) to $446 \mathrm{~mA} \mathrm{~h} \mathrm{~g}^{-1}$ (at $20 \mathrm{mAg}^{-1}$ ) [37]. Pan et al. prepared a hollow $\mathrm{MoO}_{2}$ microsphere and evaluated it as cathode for $\mathrm{Mg}$-Li hybrid batteries [38]. Both $\mathrm{Mg}^{2+}$ and $\mathrm{Li}^{+}$intercalations occur on the cathode side, and $\mathrm{Li}^{+}$contributes more capacity. In view of limited capacity (an initial discharge capacity of $217.2 \mathrm{mAh} \mathrm{g}^{-1}$ with the $\mathrm{CE}$ of $88 \%$ at $20 \mathrm{mAg}^{-1}$ ) and operating voltage $(\sim 0.8 \mathrm{~V})$, compared with other batteries described in this review, batteries using $\mathrm{MoO}_{2}$ as cathode do not have the value of continuing research.

The natrium superionic conductor (NASICON) $\mathrm{N}_{x} \mathrm{M}_{2}\left(\mathrm{PO}_{4}\right)_{3}(\mathrm{M}=$ transition metal and $\mathrm{N}=\mathrm{Li}$ or $\mathrm{Na})$ structure has been considered a promising electrode due to the existence of 3D large open framework that allows facile ion diffusion. $\mathrm{LiTi}_{2}\left(\mathrm{PO}_{4}\right)_{3}$ (LTP) has been investigated in aqueous LIBs. It has a high insertion voltage of $1.71 \mathrm{~V}$ (vs. $\mathrm{Mg} / \mathrm{Mg}^{2+}$ ) and can provide a relatively high theoretical energy density $\left(\sim 240 \mathrm{Wh} \mathrm{kg}^{-1}\right)$. Xu et al. prepared carbon-coated $\mathrm{LiTi}_{2}\left(\mathrm{PO}_{4}\right)_{3}$ microflowers (LTP-C) by a solvothermal method and subsequent annealing treatment [39]. The well-designed 3D hierarchical structure of LTP-C offers more efficient pathways for electron/ion transport, and especially, the 3D carbon skeleton significantly improves the charge-transfer kinetics. Thus, the LTP-C cathode delivers a reversible capacity of $136 \mathrm{~mA} \mathrm{~h} \mathrm{~g}^{-1}$ and a capacity retention of $94.0 \%$ after 400 cycles at $1 \mathrm{C}$, when assembled with $\mathrm{Mg}$ anode in APC-LiCl electrolyte. Moreover, the energy density of this hybrid system is estimated to be $220 \mathrm{Wh} \mathrm{kg}^{-1}$. Sun et al. investigated the electrochemical performance of two iron Prussian blue analogue (PBA) cathodes with different hydration water contents $\left(\mathrm{Fe}\left[\mathrm{Fe}(\mathrm{CN})_{6}\right]_{0.95} \cdot 2.3 \mathrm{H}_{2} \mathrm{O}\right.$ and $\mathrm{Fe}\left[\mathrm{Fe}(\mathrm{CN})_{6}\right]_{0.95} \cdot 0.7 \mathrm{H}_{2} \mathrm{O}$, denoted as 23-PBA and 07-PBA, respectively) coupled with an $\mathrm{APC}-\mathrm{LiCl}$ dual-salt electrolyte and a $\mathrm{Mg}$ anode [40]. Due to strong $\pi$-backbonding, cyanoligands improve the chlorination resistance of PBA. PBA is a cubic structure with an open framework and large interstitial sizes to allow smooth ion intercalation. Both the PBA materials were performed in dual-salt electrolyte of $0.2 \mathrm{M} \mathrm{APC}$ and $\mathrm{LiCl}$ with different concentrations in three-electrode cell configuration at a current density of $10 \mathrm{mAg}^{-1}$. When the $\mathrm{LiCl}$ concentration increases up to $0.5 \mathrm{M}$, the highest discharge capacity attained is $125 \mathrm{~mA} \mathrm{hg}^{-1}$ for both 23-PBA and $07-$ PBA. Unlike the case that $\mathrm{Li}^{+}$concentration affects the insertion mechanism of $\mathrm{Mo}_{6} \mathrm{~S}_{8}$, whether the presence or absence of $\mathrm{Li}^{+}$in the electrolyte, $\mathrm{Mg}^{2+}$ will not intercalate into the PBA structures from APC electrolyte. Long-term cycling of both materials was tested in coin cells at $200 \mathrm{mAg}^{-1}$, and 07-PBA exhibits the higher discharge capacity and better stability (65 $\mathrm{mA} \mathrm{h} \mathrm{g}^{-1}$ after 300 cycles). The release of more structural water into the electrolyte degrades the performance of 23-PBA. Despite the fact that the release of structural water may weaken electrochemical performance during cycling, it has a beneficial effect on the operating voltage.
3.2. Improvement of Low-Temperature Performance by DualSalt Electrolyte. In addition to the electrochemical performance in the conventional environment, the evaluation of low-temperature performance of battery is also of great significance. The low-temperature batteries can be used to design special energy storage devices for aerospace and deepsea exploration and military missions. It is worth mentioning that THF with low viscosity and melting point makes THFbased dual-salt electrolyte have a natural advantage in extremely low temperature environment. In addition, $\mathrm{LiCl}$ also plays a significant role in resisting the freezing of solution, and as its concentration increases, the freezing point is lower. Thanks to the perfect combination of APC/THF and $\mathrm{LiCl}$, $\mathrm{Mg}$-Li hybrid batteries exhibit low-temperature performance that should be worthy of further development. But currently, there are only two reports about the low temperature performance on polyanion-compound cathode materials.

$\mathrm{LiFePO}_{4}$ (LFP) as a classical cathode for LIBs is also investigated in Mg-Li hybrid system. When the prototype of the Mg-Li hybrid system was born, Yagi et al. tried to use LFP as cathode to confirm the concept of the dual-salt system [4]. Unfortunately, limited by the narrow electrochemical window $(\sim 2.5 \mathrm{~V}$ vs. $\mathrm{Mg})$, the charge capacity is only $60 \mathrm{~mA} \mathrm{~g}^{-1}$. Subsequently, Zhang et al. adopted a pouch cell configuration based on LFP cathode, a flexible pyrolytic graphitic film as a current collector and APC-LiCl electrolyte to obtain an Mg-Li hybrid battery with a maximum energy density of $382.2 \mathrm{~W} \mathrm{~h} \mathrm{~kg}^{-1}$ [41]. Notably, at $0^{\circ} \mathrm{C}$, the LIB based on carbonate-based electrolyte still shows a slight advantage in capacity, and when the temperature is lower (from -10 to $-40^{\circ} \mathrm{C}$ ), the hybrid system outperforms its LIB counterpart. Rashad et al. tested $\mathrm{Li}_{3} \mathrm{~V}_{2}\left(\mathrm{PO}_{4}\right)_{3}$ (LVP) in $\mathrm{Mg}\left(\mathrm{BH}_{4}\right)_{2}$ $\mathrm{LiBH}_{4} /$ diglyme and APC-LiCl/THF electrolytes [42]. The performance of LVP at room temperature (with a reversible capacity of $147.8 \mathrm{~mA} \mathrm{~h} \mathrm{~g}^{-1}$ at $50 \mathrm{~mA} \mathrm{~g}^{-1}$ ) is not as good as other cathodes mentioned in this review; nevertheless, it can operate at lower temperature (from 0 to $-40^{\circ} \mathrm{C}$ ) and may be applied under extreme conditions. As shown in Figures 2(e) and 2(f), the low temperature performance of APC-LiCl/THF hybrid system (with reversible capacities of $117,93.4$, and $63.1 \mathrm{~mA} \mathrm{hg}^{-1}$ at $0,-20$, and $-40^{\circ} \mathrm{C}$, respectively) is better than that of the corresponding LIB systems. This advantage can be ascribed to the lower polarization of $\mathrm{Mg}$-Li hybrid electrolytes. For $\mathrm{Mg}\left(\mathrm{BH}_{4}\right)_{2}-\mathrm{LiBH}_{4} /$ diglyme system, its performance at $-20^{\circ} \mathrm{C}$ is still better than that of the corresponding LIBs. When the temperature decreases to $-30^{\circ} \mathrm{C}$, the diglyme-based electrolyte freezes, resulting in a negligible capacity. Therefore, the above experiments confirm that the APC-LiCl/THF electrolyte has a noteworthy advantage in low temperature performance.

3.3. Pseudocapacitance Behavior Dominated by $\mathrm{Li}^{+}$. Fast charging technology is an inevitable trend for future development of energy storage field, and pseudocapacitance effect has aroused widespread interest due to the possibility of achieving energy storage with simultaneous high power and high energy density [43]. For the Mg-Li hybrid system, there is also a considerable pseudocapacitance contribution dominated by $\mathrm{Li}^{+}$, which can further improve the rate performance. 
$\mathrm{Su}$ et al. investigated the capacitive contribution of onedimensional mesoporous monoclinic $\mathrm{TiO}_{2}(\mathrm{~B})$ nanoflake cathode by hydrothermal synthesis in $\mathrm{Mg}$ - Li hybrid system [44]. In the pure $\mathrm{Mg}\left(\mathrm{BH}_{4}\right)_{2}$ electrolyte, $\mathrm{Mg}^{2+}$ neither inserts into $\mathrm{TiO}_{2}(\mathrm{~B})$ nanoflakes nor participates in the pseudocapacitive reaction. After adding $\mathrm{Li}^{+}, \mathrm{Mg}$ may be activated and the cointercalation of $\mathrm{Li}^{+}$and $\mathrm{Mg}^{2+}$ may contribute to the improved performance of the hybrid batteries. Compared with $\mathrm{TiO}_{2}(\mathrm{~B}) \mid \mathrm{Li}$ cells, even the enhanced pseudocapacitive behavior is observed in $\mathrm{Mg}$ - $\mathrm{Li}$ cells with $\mathrm{Mg}\left(\mathrm{BH}_{4}\right)_{2}+\mathrm{LiB}$ $\mathrm{H}_{4}$ /tetraglyme electrolyte. In view of the contribution of pseudocapacitive reaction and fast ion transport promoted by mesoporous nanoflakes, the hybrid batteries deliver excellent rate performance with $130 \mathrm{mAhg}^{-1}$ at $1 \mathrm{C}$ up to 3000 cycles and $115 \mathrm{~mA} \mathrm{~h} \mathrm{~g}^{-1}$ at $2 \mathrm{C}$ up to 6000 cycles.

MXene is a kind of transition-metal carbides/nitrides with a two-dimensional layered structure, which can be applied in electrode materials due to their unique physical and chemical properties. Liu et al. reported the prelithiated $\mathrm{V}_{2} \mathrm{C}$ MXene in Mg-Li hybrid system [45]. First, $\mathrm{V}_{2} \mathrm{C}$ MXene nanosheets are fabricated by selective etching, and then, $\mathrm{Li}$ foil is attached to $\mathrm{V}_{2} \mathrm{C}$ to obtain the prelithiated $\mathrm{V}_{2} \mathrm{C}$ via a self-discharge mechanism. By electrochemical lithiation, the interlayer spacing of $\mathrm{V}_{2} \mathrm{C}$ is significantly expanded and the consumption of $\mathrm{Li}$ caused by the formation of the solid electrolyte interphase (SEI) film on the $\mathrm{V}_{2} \mathrm{C}$ surface is compensated. The proposed reaction mechanism in the $\mathrm{Mg}-\mathrm{Li}$ hybrid battery is shown in the following equations: $\mathrm{V}_{2} \mathrm{C}+$ $0.15 \mathrm{Li}^{+}+0.15 \mathrm{e}^{-} \longrightarrow \mathrm{Li}_{0.15} \mathrm{~V}_{2} \mathrm{C}$ and $\mathrm{Li}_{0.15} \mathrm{~V}_{2} \mathrm{C}+0.44 \mathrm{Mg}^{2+}$ $+0.35 \mathrm{Li}^{+}+1.23 \mathrm{e}^{-} \leftrightarrow \mathrm{Mg}_{0.44} \mathrm{Li}_{0.5} \mathrm{~V}_{2} \mathrm{C}$ at the cathode side. Due to the structurally flexible interlayer, a charge storage mechanism with a combination of both electrostatic and faradaic natures is observed in MXene. The capacitive contribution to the total capacity for $\mathrm{V}_{2} \mathrm{C}$ is $\sim 40.2 \%$ at $0.5 \mathrm{mV} \mathrm{s}^{-1} . \mathrm{Li}^{+}$in the dual-salt electrolyte can utilize the desirable pseudocapacitance contribution to achieve faster charge storage and more excellent rate performance.

Wadsley-Roth phase oxide electrode materials for LIBs, such as $\mathrm{Nb}_{2} \mathrm{O}_{5}$, exhibit a larger pseudocapacitive contribution, thereby allowing rapid charging and discharging. Maletti et al. evaluated the ability of $\mathrm{TiNb}_{2} \mathrm{O}_{7}$ (TNO) and $\mathrm{VNb}_{9} \mathrm{O}_{25}$ (VNO) in Mg-Li hybrid batteries [46]. Both the materials have $\mathrm{ReO}_{3}$-like structure with shear planes. Compared with VNO, the migration of TNO on the (hol) plane is more favored. For microsized TNO and VNO synthesized by high-temperature solid state reaction, Mg-Li hybrid batteries provide a comparable capacity to LIBs at room temperature $\left(220 \mathrm{mAhg}^{-1}\right.$ for TNO and $150 \mathrm{mAhg}^{-1}$ for VNO both at $0.1 \mathrm{C}$ ) and exhibit even better capacity retention than LIBs. Notably, $78 \%$ and $70 \%$ of the total capacities come from the capacitive contribution at $0.1 \mathrm{mV} \mathrm{s}^{-1}$ for TNO (Figure 2(g)) and VNO, respectively. These capacitive storage values are very close to that observed in Li batteries, which indicates the Mg-Li hybrid batteries can achieve fast charging technology comparable to $\mathrm{Li}$ batteries. Subsequently, Maletti et al. further investigated the structural evolution and cycling behavior of TNO electrodes in $\mathrm{Mg}-\mathrm{Li}$ hybrid batteries [47]. Some initial Li insertion into TNO to expand the interlayers can facilitate $\mathrm{Mg}^{2+}$ coinsertion start- ing from the composition $\mathrm{Li}_{0.2} \mathrm{TiNb}_{2} \mathrm{O}_{7}$. However, due to the much slower $\mathrm{Mg}^{2+}$ diffusion kinetics, the $\mathrm{Mg}$ insertion into TNO may only be observed at a low current density. Compared with LMBs, Mg-Li hybrid batteries with nanoscale TNO have no advantage in capacity and capacity retention at room temperature. When operated at $60^{\circ} \mathrm{C}$, as seen in Figure 2(h), Mg-Li hybrid batteries exhibit an extraordinary stable high-rate cycling capability (with a capacity retention of $86 \%$ after 500 cycles at $20 \mathrm{C}$ rate), while the capacity retention of corresponding LMBs is only $16 \%$ likely due to the disintegration of SEI on $\mathrm{Li}$ anode at $\sim 60^{\circ} \mathrm{C}$. Although the operating voltage is not high and the capacity is limited, the high-rate performance exhibited by TNO seems to have commercial prospects. However, its performance in $\mathrm{Mg}-\mathrm{Li}$ hybrid battery is excessively dependent on temperature, and more modification is needed to make it appropriate for commercial use.

Organic materials are also a class of promising candidate for cathodes because of their low cost and structural designability. Due to the existence of high-density carbonyl groups $(\mathrm{C}=\mathrm{O})$ as redox sites, sodium rhodizonate $\left(\mathrm{Na}_{2} \mathrm{C}_{6} \mathrm{O}_{6}\right)$ and lithium rhodizonate $\left(\mathrm{Li}_{2} \mathrm{C}_{6} \mathrm{O}_{6}\right)$ with theoretical capacities of 501 and $580 \mathrm{mAhg}^{-1}$, respectively, have been reported as cathodes for Li-ion and $\mathrm{Na}$-ion batteries. The crystal structure of $\mathrm{Na}_{2} \mathrm{C}_{6} \mathrm{O}_{6}$ which is composed of layers of $\mathrm{C}_{6} \mathrm{O}_{6}{ }^{2-}$ and $\mathrm{Na}^{+}$is located between the anion layers. $\mathrm{Na}_{2} \mathrm{C}_{6} \mathrm{O}_{6}$ has higher conductivity and lower solubility than $\mathrm{Li}_{2} \mathrm{C}_{6} \mathrm{O}_{6}$ due to larger-sized cation substitution. Tian et al. prepared the nanosized $\mathrm{Na}_{2} \mathrm{C}_{6} \mathrm{O}_{6}$ by the antisolvent crystallization method to further improve its charge transport capacity [48]. Due to the sluggish $\mathrm{Mg}^{2+}$ in host lattices, $\mathrm{Na}_{2} \mathrm{C}_{6} \mathrm{O}_{6}$ only delivers a negligible capacity in the APC electrolyte system. In the $\mathrm{APC}-\mathrm{LiCl}$ system, since $\mathrm{Li}^{+}$with less steric hindrance dominantly inserts into cathode, instead of high-polarity $\mathrm{Mg}^{2+}$, the capacity of $\mathrm{Na}_{2} \mathrm{C}_{6} \mathrm{O}_{6}$ is significantly improved. The $\mathrm{Mg}-\mathrm{O}-\mathrm{C}$ and $\mathrm{Li}-\mathrm{O}-\mathrm{C}$ peaks detected by X-ray photoelectron spectroscopy (XPS) indicate a cointercalation of $\mathrm{Mg}^{2+}$ and $\mathrm{Li}^{+}$into $\mathrm{Na}_{2} \mathrm{C}_{6} \mathrm{O}_{6}$. Irreversible trapping of a small amount of $\mathrm{Mg}^{2+}$ could alleviate the structure destruction and exfoliation of the $\mathrm{C}_{6} \mathrm{O}_{6}$ layers during charging and improve cycle stability. The reaction mechanism of $\mathrm{Na}_{2} \mathrm{C}_{6} \mathrm{O}_{6}$ is shown in Figure 3(a). Mg-Li hybrid batteries with $\mathrm{Na}_{2} \mathrm{C}_{6} \mathrm{O}_{6}$ cathode show a high discharge capacity of $\sim 450 \mathrm{~mA} \mathrm{~h} \mathrm{~g}^{-1}$ based on four-electron transfer in the first cycle. A reversible three-electron transfer reaction based on $\mathrm{Na}_{2} \mathrm{Li}_{4} \mathrm{C}_{6} \mathrm{O}_{6} / \mathrm{Na}_{2}$ $\mathrm{LiC}_{6} \mathrm{O}_{6}$ occurs in the subsequent cycles, providing a discharge capacity of $\sim 350 \mathrm{~mA} \mathrm{~h}^{-1}$ at $50 \mathrm{mAg}^{-1}$. In addition, as seen in Figure $3(\mathrm{~b}), \mathrm{Na}_{2} \mathrm{C}_{6} \mathrm{O}_{6}$ delivers an outstanding high-rate performance with 200 and $175 \mathrm{mAhg}^{-1}$ at $2.5 \mathrm{~A}$ $\mathrm{g}^{-1}(5 \mathrm{C})$ and $5 \mathrm{~A} \mathrm{~g}^{-1}(10 \mathrm{C})$, respectively, which also benefits from the reduced graphene oxide (rGO) network with quick charge transfer ability and the capacitive contribution of $60 \%-65 \%$ at various scan rates from 0.4 to $1 \mathrm{mV} \mathrm{s}^{-1}$ (Figure 3(c)). The application of rhodizonate salt cathodes has the potential to obtain high energy-density and powerdensity Mg-Li hybrid batteries. A less soluble and more conductive rhodizonate salt can be obtained by replacing pillar ions. Tian et al. also synthesized $\mathrm{K}_{2} \mathrm{C}_{6} \mathrm{O}_{6}$ with ultra-large microsized grains (up to $30 \mu \mathrm{m}$, Figure 3(d)) [49]. Compared 

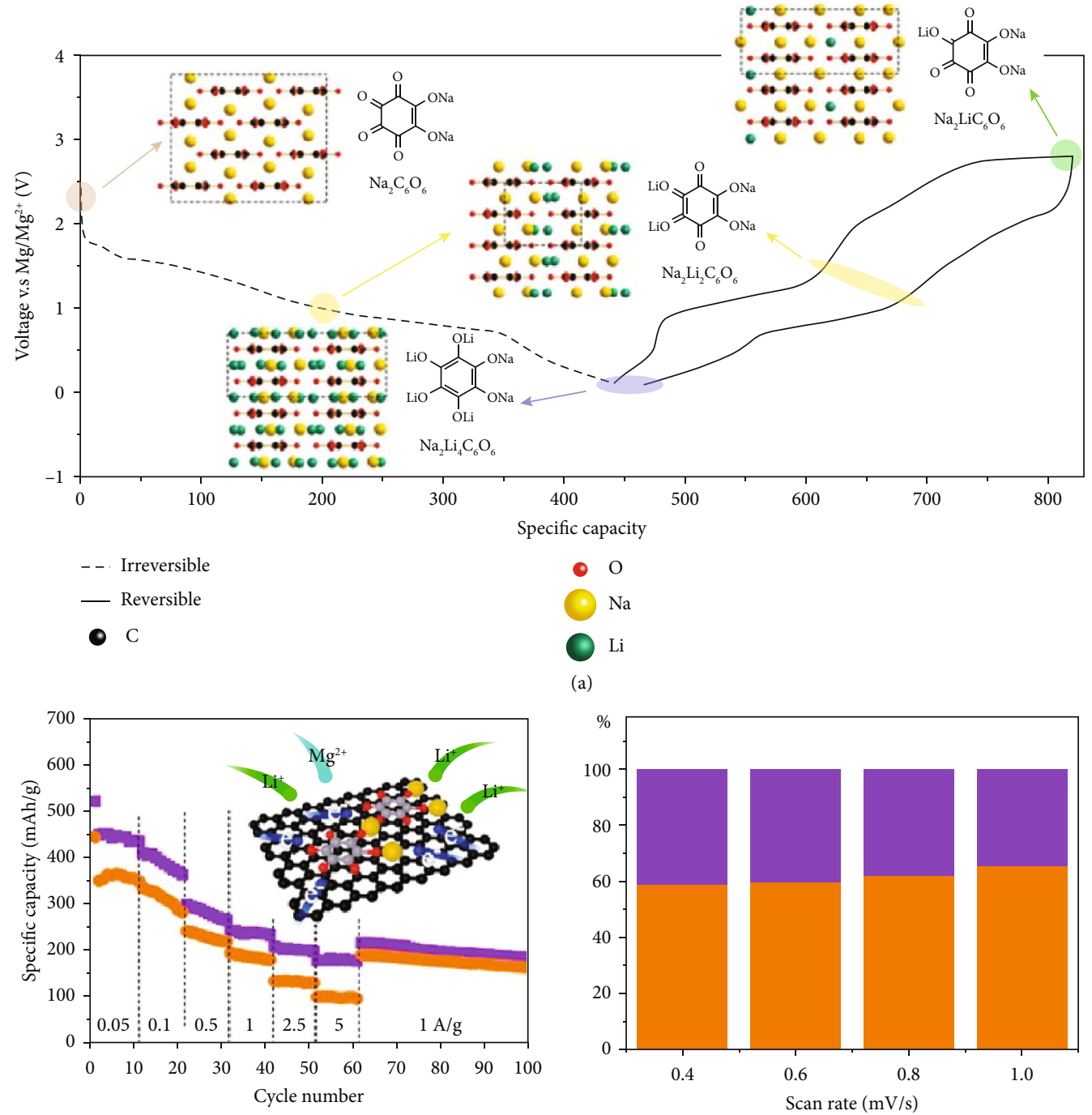

- $\mathrm{rGO}$

- Super P

Intercalated

Capacitive

(b)

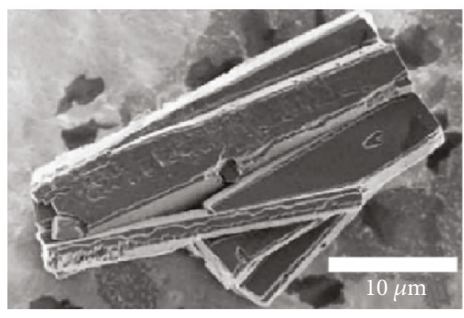

(d)

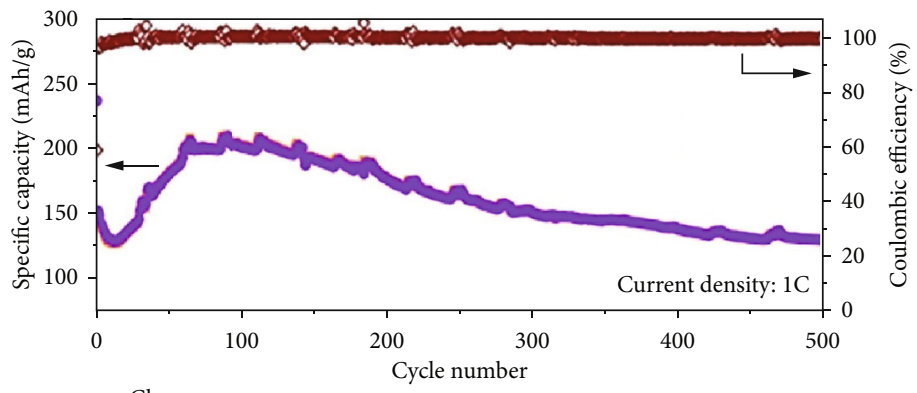

- Charge

- Discharge

(e)

FIgURE 3: (a) Scheme of proposed redox mechanism and structure change of $\mathrm{Na}_{2} \mathrm{C}_{6} \mathrm{O}_{6}$ during cycling. (b) Rate performance comparison of $\mathrm{Na}_{2} \mathrm{C}_{6} \mathrm{O}_{6}$ wired by Super P and rGO. Inset: schematic illustration of cointercalation of Li and $\mathrm{Mg}$ into $\mathrm{Na}_{2} \mathrm{C}_{6} \mathrm{O}_{6}$ molecules hybridized with rGO network. (c) Column graphs of rate-dependent charge storage contributions from both capacitive and intercalated processes for $\mathrm{Na}_{2} \mathrm{C}_{6} \mathrm{O}_{6}$ [48]. (d) SEM image of $\mathrm{K}_{2} \mathrm{C}_{6} \mathrm{O}_{6}$ powder. (e) Charge-discharge capacity and CE of Mg-Li hybrid battery based on $\mathrm{K}_{2} \mathrm{C}_{6} \mathrm{O}_{6}$ cathode at $1 \mathrm{C}$ [49]. 
with $\mathrm{Na}_{2} \mathrm{C}_{6} \mathrm{O}_{6}$, the semiconductivity of $\mathrm{K}_{2} \mathrm{C}_{6} \mathrm{O}_{6}$ endows it with the less use of conductive carbon to compensate for conductivity insufficiency. After charging, $\mathrm{K}^{+}$with larger volume and lower charge density is extruded from $\mathrm{C}_{6} \mathrm{O}_{6}{ }^{2-}$ by the injection of $\mathrm{Mg}^{2+}$ and $\mathrm{Li}^{+}$, and no serious grain cracking and pulverization is observed during this process. The reaction mechanism of $\mathrm{K}_{2} \mathrm{C}_{6} \mathrm{O}_{6}$ in $\mathrm{Mg}$ - $\mathrm{Li}$ hybrid batteries is similar to that of $\mathrm{Na}_{2} \mathrm{C}_{6} \mathrm{O}_{6} \cdot \mathrm{K}_{2} \mathrm{C}_{6} \mathrm{O}_{6}$ exhibits a reversible capacity more than $300 \mathrm{mAhg}^{-1}$ (based on a threeelectron transfer reaction) at $0.1 \mathrm{C}$ and an excellent cycling performance (at least 500 cycles at $1 \mathrm{C}$, Figure 3(e)). And the capacitive contribution of $40 \%-50 \%$ compensates for faradaic intercalation capacity at higher voltage region, thus, $\mathrm{K}_{2} \mathrm{C}_{6} \mathrm{O}_{6}$ has a good rate performance with the capacities of 200,130 , and $60 \mathrm{~mA} \mathrm{~h} \mathrm{~g}^{-1}$ at $2 \mathrm{C}, 5 \mathrm{C}$, and $10 \mathrm{C}$, respectively.

3.4. Boost of Conversion Reaction from $\mathrm{Li}^{+}$. Compared with intercalation-type cathodes, the research on conversiontype cathodes started later, but they have attracted widespread attention as potential high-energy-density alternatives to traditional intercalation-type cathodes for rechargeable batteries. For a typical conversion reaction, metal ions first diffuse into the host material, and then structural rearrangement and chemical bond rupture occur, accompanied by the release of a high capacity. These phase transitions are generally electrochemically reversible. Typical conversion-type cathode materials include metal chalcogenides and metal fluorides, etc. However, MMBs face the problem of kinetically sluggish $\mathrm{Mg}^{2+}$ diffusion into host material. Mg-Li hybrid electrolyte opens up a new avenue for the application of conversion-type cathodes in Mg-based batteries.

As resource-abundant $\mathrm{FeS}_{2}$ and $\mathrm{FeS}$ have very high theoretical capacities of 894 and $609 \mathrm{~mA} \mathrm{~h} \mathrm{~g}^{-1}$, respectively, it is attractive to apply them in energy storage batteries. Zhang et al. reported the Mg-Li hybrid batteries based on conversion type $\mathrm{FeS}_{2}$ and $\mathrm{FeS}$ cathodes [50]. Due to the presence of electrophilic polysulfides, when the addition of $\mathrm{Li}$ salt is sufficient, nonnucleophilic $\mathrm{Mg}\left(\mathrm{BH}_{4}\right)_{2}$-based electrolyte exhibits better rate and reversibility performance than that in the nucleophilic APC-based electrolyte. Under the optimized concentration and cutoff voltage conditions, the hybrid batteries perform better than $\mathrm{Li} / \mathrm{FeS}_{\mathrm{x}}$ ones (Figure 4(a)), benefitting from dendrite-free $\mathrm{Mg}$ anode with potential SEI decoration, which can shield the corrosion of polysulfides. Although it is thermodynamically preferential for $\mathrm{Mg}$ to drive the conversion reaction, the process is actually controlled by kinetics. Therefore, the hybrid batteries perform according to the following reactions (Figure 4(b)): $\mathrm{FeS}_{2}+2 \mathrm{Mg}+4 \mathrm{Li}^{+} \longrightarrow \mathrm{Fe}^{0}+2 \mathrm{Li}_{2} \mathrm{~S}+2 \mathrm{Mg}^{2+} ; \mathrm{FeS}+\mathrm{Mg}+2 \mathrm{~L}$ $\mathrm{i}^{+} \longrightarrow \mathrm{Fe}^{0}+\mathrm{Li}_{2} \mathrm{~S}+\mathrm{Mg}^{2+}$. Although the S-deficient $\mathrm{Fe}_{7} \mathrm{~S}_{8}$ and $\mathrm{Li}_{2} \mathrm{FeS}_{2}$ are formed during the charging process, resulting in irreversible capacity loss, the combination of $\mathrm{FeS}_{2}$ and $\mathrm{Mg}$ can achieve a high energy density close to $400 \mathrm{Wh} \mathrm{kg}^{-1}$.

Chen et al. improved the electrochemical performance of FeS by designing a free-standing membrane electrode with FeS nanoparticles embedded in carbon nanofibers (CNFs) via a facile electrospinning method [51]. Benefitting from sufficient electron transport channels and the accommoda- tion for large volumetric change during cycling, the FeSCNF cathode exhibits an outstanding long-term cycling performance (with a stable capacity of $\sim 200 \mathrm{~mA} \mathrm{~h} \mathrm{~g}^{-1}$ after 800 cycles) at a current density of $257 \mathrm{~mA} \mathrm{~g}^{-1}$ in the $0.4 \mathrm{M}$ APC-0.4 M LiCl electrolyte. Together with the absence of the current collector and binder, the energy density of this system can reach up $\sim 300 \mathrm{Wh} \mathrm{kg}^{-1}$, and it is a promising candidate for the application in flexible devices.

$\mathrm{Cu}$-based chalcogenides have attracted great attention due to their desirable theoretical capacities, such as $560 \mathrm{mAhg}^{-1}$ for $\mathrm{CuS}$ and $337 \mathrm{mAhg}^{-1}$ for $\mathrm{Cu}_{2} \mathrm{~S}$, but they are troubled by poor kinetic performance and need to be operated at an elevated temperature or extremely low current density. Li et al. used a hyperbranched polymer template to synthesize microflowers $\mathrm{Cu}_{9} \mathrm{~S}_{5}$ with a reversible capacity of $300 \mathrm{~mA} \mathrm{~h} \mathrm{~g}^{-1}$ at $50 \mathrm{mAg}^{-1}$ [52]. Due to the electrochemical irreversibility of $\mathrm{Li}_{2} \mathrm{~S}$ after the first discharge process, $\mathrm{Cu}_{9} \mathrm{~S}_{5}$ converts to $\mathrm{Cu}_{1.96} \mathrm{~S}$ and the subsequent cycles follow the equation: $1.96 \mathrm{Cu}+\mathrm{Li}_{2} \mathrm{~S} \leftrightarrow \mathrm{Cu}_{1.96} \mathrm{~S}+2 \mathrm{Li}^{+}+2 \mathrm{e}^{-}$. $\mathrm{Wu}$ et al. combined dual-salt electrolyte $(0.25 \mathrm{M} \mathrm{APC}+1.0 \mathrm{M} \mathrm{LiCl})$ and well-designed cathodes $\left(\mathrm{Cu}_{1.96} \mathrm{~S}-\mathrm{MoS}_{2}-\mathrm{MoO}_{2}\right.$ and $\left.\mathrm{Cu}_{2} \mathrm{Se}-\mathrm{MoO}_{2}\right)$ with nanowiring and hierarchical structure to obtain the maximum reversible capacities more than $200 \mathrm{~mA} \mathrm{hg}^{-1}$ [53]. They selected the Cu-based metal-organic framework (MOF) HKUST-1 $\left(\left[\mathrm{Cu}_{3}(\mathrm{BTC})_{2}\left(\mathrm{H}_{2} \mathrm{O}\right)_{\mathrm{x}}\right]_{\mathrm{n}}\right)$ with large specific surface area and rich pores as precursor and infiltrated the Keggin-type polyoxometalate anion $\left(\left[\mathrm{P}\left(\mathrm{Mo}_{12} \mathrm{O}_{40}\right)\right]^{3-}\right)$ into the voids of HKUST-1 to form POM $\subset$ MOF $\left(\left[\mathrm{Cu}_{2}(\mathrm{BTC})_{4 / 3}\left(\mathrm{H}_{2} \mathrm{O}\right)_{2}\right]_{6}\left[\mathrm{H}_{3} \mathrm{PMo}_{12} \mathrm{O}_{40}\right]\right.$, denoted as NENU-5) as a composite template. Then, $\mathrm{S}$ NENU $\left(\mathrm{Cu}_{1.96} \mathrm{~S}-\mathrm{MoS}_{2}-\mathrm{MoO}_{2}\right)$ and Se-NENU $\left(\mathrm{Cu}_{2} \mathrm{Se}-\mathrm{MoO}_{2}\right)$ were synthesized by thermal sulfuration and selenylation, respectively. The $\mathrm{Cu}_{2-y} \mathrm{X}(\mathrm{X}=\mathrm{S}, \mathrm{Se})$ nanosheets of S-NENU and Se-NENU are modulated by C-coated $\mathrm{MoO}_{2}$ pompons as conductive stakes, which can prevent the adherence (or aggregation) of surrounding $\mathrm{Cu}_{2-y} \mathrm{X}$ nanosheets. In addition, a dominant Li-driven insertion-conversion behavior in dual-salt electrolyte further improves the reaction kinetics. Therefore, both the composite cathodes exhibit good long-term cycling performance with a $\mathrm{CE}$ value close to $100 \%$ at room temperature. Wang et al. also prepared carbon-encapsulated cuprous sulfide $\left(\mathrm{Cu}_{2} \mathrm{~S} @ \mathrm{C}\right)$ composite cathode via a MOF-derived sulfurization method [54]. Combing with the nonnucleophilic HMDS-based hybrid electrolyte, $\mathrm{Cu}_{2} \mathrm{~S} @ \mathrm{C}$ shows the enhanced performance due to the alleviation of sulfide dissolution.

Cobalt sulfide $\left(\mathrm{CoS}_{2}\right)$ has also become a candidate of conversion cathode materials in the $\mathrm{Mg}-\mathrm{Li}$ hybrid system in view of its theoretical capacity as high as $870 \mathrm{~mA} \mathrm{~h} \mathrm{~g}^{-1}$. To alleviate the volume expansion of $\mathrm{CoS}_{2}$ and avoid electrode pulverization during cycle, Asif et al. designed porous Ni/Zn codoped $\mathrm{CoS}_{2} @ \mathrm{C}$ spheres [55]. In APC-LiCl hybrid electrolyte, $\mathrm{Li}^{+}$reacts with $\mathrm{CoS}_{2}$ instead of $\mathrm{Mg}^{2+}$, avoiding the formation of undissolved $\mathrm{MgS}$ and enhancing the conversion reversibility and cycle stability. The MOF-derived sulfurization method also was applied to fabricate $\operatorname{CoS}_{2} / \mathrm{C}$ composite nanotube array electrode [56]. For Li batteries, discharge depth can affect the capacity retention. Thus, together with an appropriate working voltage range in $\mathrm{Mg}$ Li hybrid batteries $\left(0.01-2.0 \mathrm{~V}\right.$ vs. $\mathrm{Mg}^{2+} / \mathrm{Mg}$ corresponding 


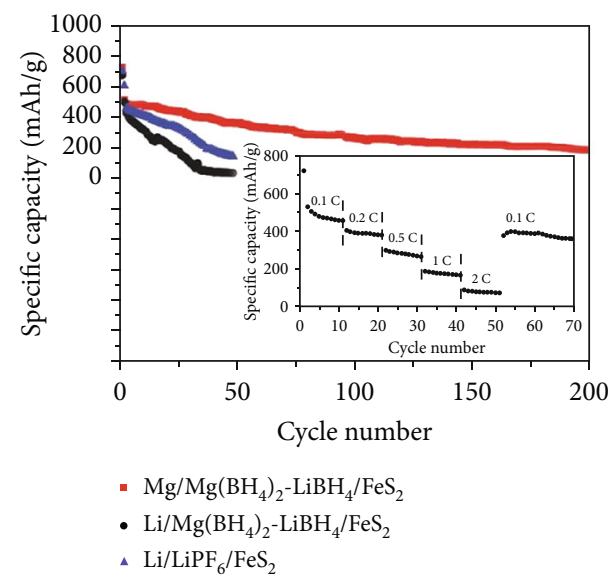

(a)

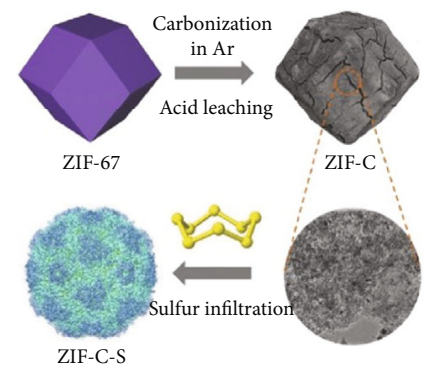

(d)
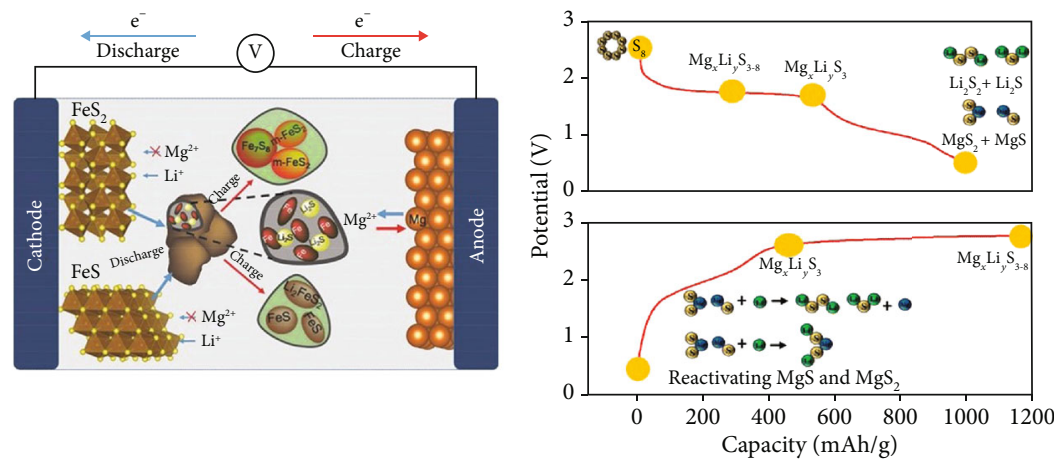

(b)

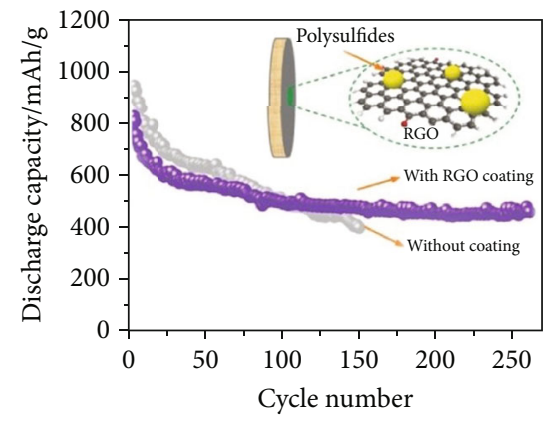

(e) (c)

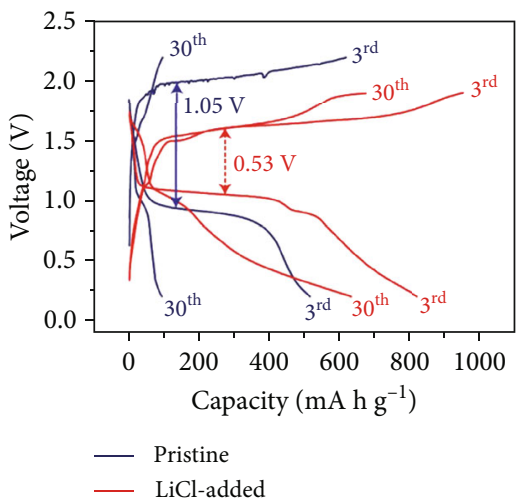

(f)

Figure 4: (a) Cycling performance comparison of $\mathrm{Mg} / \mathrm{Mg}\left(\mathrm{BH}_{4}\right)_{2}-\mathrm{LiBH}_{4} / \mathrm{FeS}_{2}, \mathrm{Li} / \mathrm{Mg}\left(\mathrm{BH}_{4}\right)_{2}-\mathrm{LiBH}_{4} / \mathrm{FeS}_{2}$, and Li/ $/ \mathrm{LiPF}_{6} / \mathrm{FeS}$, batteries at 0.1 $\mathrm{C}$; inset: corresponding rate performance of $\mathrm{Mg} / \mathrm{FeS}_{2}$ battery from $0.1 \mathrm{C}$ to $2 \mathrm{C}$. (b) Scheme of Li-driven conversion reaction at the FeS $\mathrm{x}_{\mathrm{x}}$ cathode coupled with $\mathrm{Mg}$ metal plating/stripping at the anode [50]. (c) Reaction mechanism of Mg/S battery with LiTFSI additive [12]. (d) Schematic illustration to prepare ZIF-C host and ZIF-C-S composition electrode [60]. (e) Capacity stability comparison between Mg and $\mathrm{S}$ batteries with separator coated by $\mathrm{rGO}$ and without separator modification at $0.1 \mathrm{C}$. (f) Galvanostatic discharge/charge curves of $\mathrm{Mg}-\mathrm{S}$ batteries with and without $\mathrm{LiCl}$ addition at different cycle stages [14].

to $0.7-2.7 \mathrm{~V}$ vs. $\left.\mathrm{Li}^{+} / \mathrm{Li}\right)$, the $\mathrm{CoS}_{2} / \mathrm{C}$ cathode exhibits a remarkable cycling performance $\left(225.4 \mathrm{~mA} \mathrm{~h} \mathrm{~g}^{-1}\right.$ after 2000 cycles at $\left.1 \mathrm{~A} \mathrm{~g}^{-1}\right)$.

Zhu et al. studied the performance of $\mathrm{NiSe}_{2} / \mathrm{Ti}_{3} \mathrm{C}_{2}$ in Mg-Li hybrid batteries [57]. 2D MXene $\mathrm{Ti}_{3} \mathrm{C}_{2}$ as a conducive matrix supports $\mathrm{NiSe}_{2}$, leading to the improved rate capability (a reversible capacity of $150 \mathrm{~mA} \mathrm{~h} \mathrm{~g}^{-1}$ at $5 \mathrm{~A} \mathrm{~g}^{-1}$ ). And the conversion reaction is expressed as follows: $3 \mathrm{NiSe}_{2}+2 \mathrm{Mg}$ $+4 \mathrm{Li}^{+} \longrightarrow \mathrm{Ni}_{3} \mathrm{Se}_{4}+2 \mathrm{Li}_{2} \mathrm{Se}+2 \mathrm{Mg}^{2+}$. However, the authors did not provide the long-term performance of $\mathrm{NiSe}_{2}$. Compared with other metal chalcogenides, $\mathrm{NiSe}_{2}$ does not offer significant breakthrough in the battery-relevant metrics.

Sulfur (S) cathode has very high theoretical gravimetric and volumetric capacities of $1672 \mathrm{~mA} \mathrm{hg}^{-1}$ and $3459 \mathrm{~mA} \mathrm{~h} \mathrm{~cm}^{-3}$, respectively. And it is expected to achieve an energy density up to $1722 \mathrm{Wh} \mathrm{kg}^{-1}$ when coupled with $\mathrm{Mg}$ metal anode. However, the development of magnesium-sulfur (Mg-S) batteries also faces considerable obstacles, including incompatibility with nucleophilic electrolytes, severe overcharge behavior of the cathode, low sulfur utilization, the formation of less dissoluble magnesium polysulfide (Mg-PS), and the slow diffusion of $\mathrm{Mg}^{2+}$. Therefore, the tailor-made electrolyte systems, cathode hosts, and separators for $\mathrm{Mg}-\mathrm{S}$ batteries are highly required.

According to the literatures, a Mg-S system based on $\mathrm{Mg}$ foil anode, sulfur cathode, and $\left(\mathrm{Mg}(\mathrm{HMDS})_{2}\right)-\mathrm{AlCl}_{3} / \mathrm{THF}$ electrolyte was first reported by Muldoon and coworkers in 2011 [58], though the capacity decay in the second cycle has exceeded $75 \%$. Later, $\mathrm{Mg}(\mathrm{TFSI})_{2}$ dissolved in glyme/diglyme was also considered a promising electrolyte for $\mathrm{Mg}$ $\mathrm{S}$ batteries. Zhao-Karger et al. used TFSI-based ionic liquid (N-methyl-N-butylpiperidinium bis(trifluoromethanesulfonyl)imide $\left(\mathrm{PP}_{14} \mathrm{TFSI}\right)$ ) as an additive and further improved the performance of $\mathrm{Mg}(\mathrm{HMDS})_{2}$-based electrolyte for $\mathrm{Mg}$ $S$ batteries [59]. Until 2015, Gao et al. proposed the positive effect of $\mathrm{Li}^{+}$on activating $\mathrm{MgS}_{\mathrm{x}}$ species [12] and enhanced the cycle stability of Mg-S batteries by adding LiTFSI into Mg-HMDS electrolyte. As shown in Figure 4(c), $\mathrm{Li}^{+}$enables the reactivation of the short chain Mg-PS through an ion exchange reaction or coordination with $\mathrm{S}^{2-}$ and $\mathrm{S}_{2}^{2-}$ on the Mg-PS surface to form readily soluble and rechargeable Li polysulfide (Li-PS) or hybrid $\mathrm{Mg} / \mathrm{Li}$ polysulfide (MgLi- 
PS). Although the loading of sulfur cathode in this work is low (15 wt\%) and the cycling ability is insufficient (only 30 cycles), it illustrates the activation effect of the dual-salt electrolyte on the Mg-S system.

In addition to exploring nonnucleophilic electrolytes that are compatible with sulfur cathodes, the design of cathode structures that alleviate sulfur dissolution and increase sulfur loading is also one of the effective ways to enhance the cycle stability of Mg-S batteries. Zhou et al. reported a high rate Mg-S battery based on a $\mathrm{Mg}$ foil anode, a S/MOF derivative cathode, and a glass fiber separator coated by reduced graphene oxide (rGO) and $\mathrm{Mg}(\mathrm{HMDS})_{2}-\mathrm{AlCl}_{3}-$ LiTFSI electrolyte [60]. Figure 4(d) shows a schematic process to prepare $S$ cathode. The authors synthesized ZIF-67 derivative carbon host (ZIF-C) by a thermal pyrolysis of ZIF-67 and acid leaching, followed by sulfur infiltration to obtain an $S$ cathode with a mass loading of $47 \%$. The Co and $\mathrm{N}$ codoped ZIF-C with hierarchical porous morphology can trap soluble polysulfides and potentially catalyze the polysulfide conversion with better kinetics. During the discharging, $\mathrm{S}_{8}$ is reduced to $\mathrm{MgS}_{x}(x>2), \mathrm{Li}_{2} \mathrm{~S}_{\mathrm{y}}, \mathrm{Mg}$-Li-S species, and small amount of $\mathrm{MgS} / \mathrm{MgS}_{2}$, which are detected by XPS. It is confirmed that the conversion process is driven by $\mathrm{Li}^{+}$and $\mathrm{Mg}^{2+}$, and the accumulation of $\mathrm{MgS}_{x}(x \leq 2)$ causes the capacity fading during long-term cycling. Since $\mathrm{Mg}$-S batteries suffer more severe shuttle effect than Li-S batteries, the rGO-modified separator is used to alleviate the shuttle effect of polysulfides (Figure 4(e)). By combining with the optimized charging protocol (with cut-off charge capacity), the synergy of multiple strategies makes better cycling stability in $\mathrm{Mg}$-S batteries. At $0.1 \mathrm{C}$ rate, the full cell based on the modified separator exhibits a slowed capacity decay trend, and the reversible capacity is $450 \mathrm{~mA} \mathrm{~h} \mathrm{~g}^{-1}$ after 250 cycles. At $1 \mathrm{C}$ rate, the first discharge capacity is as high as $600 \mathrm{~mA} \mathrm{hg}^{-1}$, and the reversible capacity is still $400 \mathrm{~mA} \mathrm{~h} \mathrm{~g}^{-1}$ after 200 cycles. Yang et al. reported a complex $\mathrm{Mg}\left(\mathrm{CF}_{3} \mathrm{SO}_{3}\right)_{2}$-based electrolyte for $\mathrm{Mg}$-S batteries [13]. The authors added $\mathrm{LiCl}$ or $\mathrm{LiCF}_{3} \mathrm{SO}_{3}$ into the solution of 0.125 $\mathrm{M} \mathrm{Mg}\left(\mathrm{CF}_{3} \mathrm{SO}_{3}\right)_{2}+0.25 \mathrm{M} \mathrm{AlCl}_{3}+0.25 \mathrm{M} \mathrm{MgCl}_{2}+0.025 \mathrm{M}$ anthracene/THF + tetraglyme (1:1 in volume ratio). Coupled with sulfur@microporous carbon cathode, the results show that $\mathrm{Li}^{+}$promotes the dissociation of $\mathrm{Mg}$-ions in the electrolyte and activates $\mathrm{MgS} / \mathrm{MgS}_{2}$ in the $\mathrm{S}$ cathode, resulting in the enhancement of specific capacity, reaction reversibility, and capacity retention. In addition, the addition of $\mathrm{LiCF}_{3} \mathrm{SO}_{3}$ enables the better performance than $\mathrm{LiCl}$, in view that $\mathrm{CF}_{3} \mathrm{SO}_{3}{ }^{-}$ions promote the $\mathrm{Mg}$ deposition/dissolution. Fan et al. achieved the reduction of overpotential and extension of cycle life of $\mathrm{Mg}$-S batteries in $\mathrm{MgCl}_{2}-\mathrm{AlCl}_{3}$ complex electrolyte by using $\mathrm{LiCl}$ additive [14]. $\mathrm{LiCl}$ not only activates the $\mathrm{S}$ cathode but also facilitates the Mg deposition/dissolution on anode side to reduce voltage polarization of full cell (Figure 4(f)). Thus, the $\mathrm{Mg}$-S batteries exhibit a remarkably stable cycling performance at $0.4 \mathrm{C}$ (with a capacity of $300 \mathrm{~mA} \mathrm{~h}^{-1}$ after 500 cycles). In addition to sulfur cathode, sulfur-rich metal polysulfides are also good candidates for high-energy-density hybrid systems. Wang et al. developed amorphous $\operatorname{MoS}_{\mathrm{x}}\left(\mathrm{x}=5.7, \mathrm{a}-\mathrm{MoS}_{5.7}\right)$ polysulfide as cathode in $\mathrm{Mg}$-Li hybrid batteries with the dis- charge mechanism of a-MoS ${ }_{5.7}+x \mathrm{Li}^{+}+x \mathrm{e}^{-} \longrightarrow \mathrm{MoS}_{5.7-0.5 x}$ $+0.5 x \mathrm{Li}_{2} \mathrm{~S}(x \leq 8.4)$ [61]. In the electrolytes without $\mathrm{LiCl}$, the large charge-transfer resistance prevents $\mathrm{Mg}^{2+}$ from diffusion in $\alpha-\mathrm{MoS}_{5.7}$; thus, $\mathrm{Mg}^{2+}$ hardly contributes to the capacity. Thanks to the fast $\mathrm{Li}^{+}$diffusion, the $\mathrm{MoS}_{5.7}$ cathode delivers a high capacity of $812 \mathrm{~mA} \mathrm{~h} \mathrm{~g}^{-1}$ with an average plateau of $1.02 \mathrm{~V}$ at $50 \mathrm{mAg}^{-1}$ and a high energy density of $761 \mathrm{Wh} \mathrm{kg}^{-1}$ is realized.

Selenium (Se) has a notable theoretical capacity (a gravimetric capacity of $678 \mathrm{mAhg}^{-1}$ and a volumetric capacity of $3268 \mathrm{~mA} \mathrm{~h} \mathrm{~cm}^{-3}$ ) and a high electronic conductivity $\left(10^{-3} \mathrm{~S} \mathrm{~m}^{-1}\right)$. Thus, Se is expected to build a system with high volumetric energy density similar to S. Similarly, the dissolution issue of high-order magnesium polyselenides still plagues the Mg-Se system. Yuan et al. prepared a selenized polyacrylonitrile (Se/PAN) cathode with a Se content of $45.37 \mathrm{wt} \%$, which was tested in APC- $\mathrm{LiCl}$ electrolyte [62]. In this system, only one plateau is observed in the discharge curve, indicating a direct interconversion between Se and Li2Se without the formation of intermediate polyselenides. Although the capacity decay is slower $(0.021 \%$ per cycle), considering the limited capacity at a higher current density $\left(118.3 \mathrm{~mA} \mathrm{hg}^{-1}\right.$ after 800 cycles at $400 \mathrm{~mA} \mathrm{~g}^{-1}$ ), the Se cathode materials need further modification.

\section{Influence of $\mathrm{Li}^{+}$on Anode in $\mathrm{Mg}-\mathrm{Li}$ Hybrid Systems}

As known, a major advantage of $\mathrm{Mg}$-Li hybrid batteries is the adoption of $\mathrm{Mg}$ metal anode with smooth deposition morphology. Especially at a rate up to $20 \mathrm{C}$ (Figure 5(a)), compared with $\mathrm{Li}$ metal batteries, although the $\mathrm{Mg}$ anode suffers a higher overpotential in APC-LiCl electrolyte, it can prevent the local concentration of current and the growth of dendrites [47]. In addition to the characteristic advantages of $\mathrm{Mg}$ anode, $\mathrm{Li}^{+}$will also have magical effects on the $\mathrm{Mg}$ anode side in the Mg-Li hybrid system, including tailoring SEI and reducing the overpotential. Li salt plays a vital role in regulating the composition of SEI on the Mg anode side. The Mg metal anode spontaneously reacts with the conventional electrolyte (salt and solvent) to form a passivation film, which is ionically and electronically insulating, on the surface of $\mathrm{Mg}$ anode. For example, a $\mathrm{Mg}$ electrolyte based on tetrakis(hexafluoroisopropyloxy)borate anion (B(hfip) ${ }_{4}{ }^{-}$), $\mathrm{Mg}\left[\mathrm{B} \text { (hfip) }{ }_{4}\right]_{2} / \mathrm{DME}$ (denoted as MBhfip/DME), is partially decomposed on the surface of $\mathrm{Mg}$ metal anode with the formation of a fragile SEI, which cannot support stable and long-term cycles. Tang et al. introduced $\mathrm{Mg}^{2+}$ into the $\mathrm{Li}$ electrolyte $\mathrm{Li}\left[\mathrm{B}(\mathrm{hfip})_{4}\right] / \mathrm{DME}$ (denoted as LBhfip/DME) through the initial electrochemical cycles [63], and the in situ formed $\mathrm{Mg}$-Li hybrid electrolyte can allow the highly reversible $\mathrm{Mg}$ plating/stripping. As shown in Figure 5(b), after a short activation period, the CE value reaches $99.0 \%$ and remains stable for 500 cycles. The stable and efficient plating/stripping behavior benefits from the formation of Li-containing SEI, by partial decomposition of LBhfip/DME electrolyte on the 


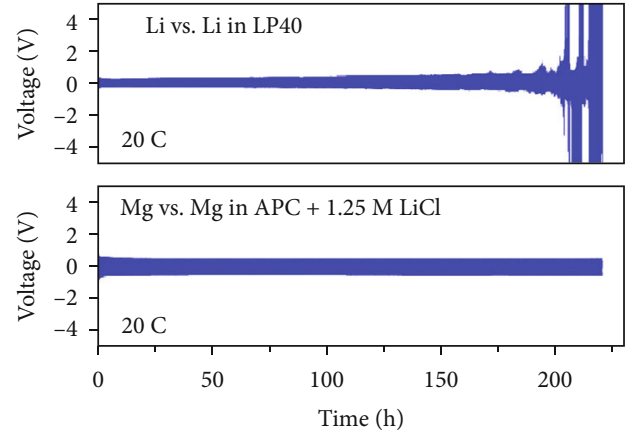

(a)

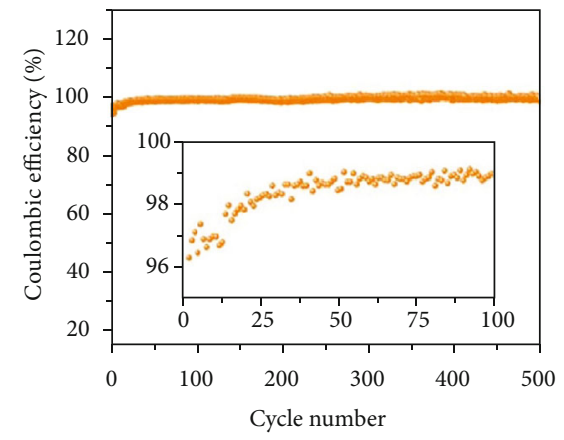

- LBhfip/DME

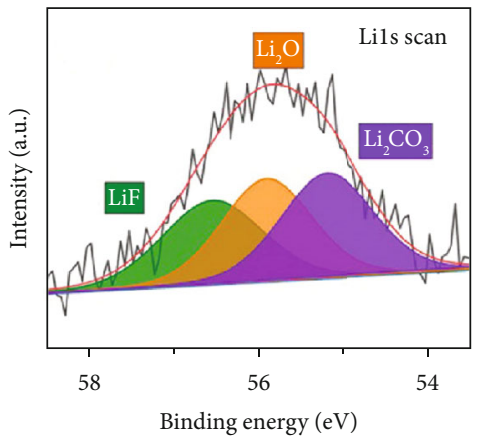

(b)

(c)

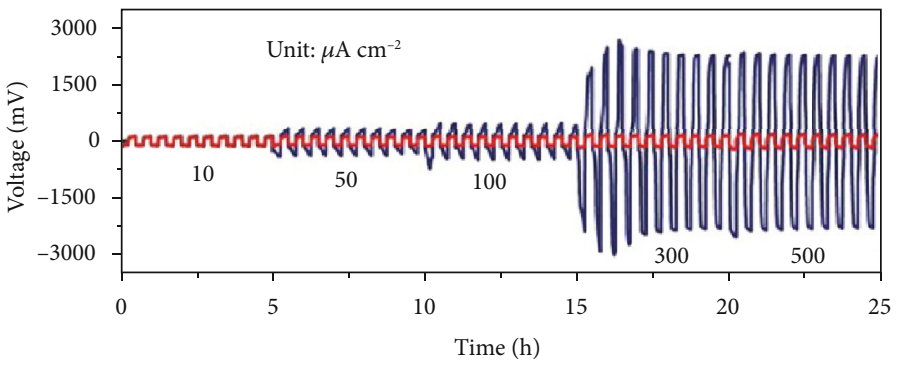

(d)

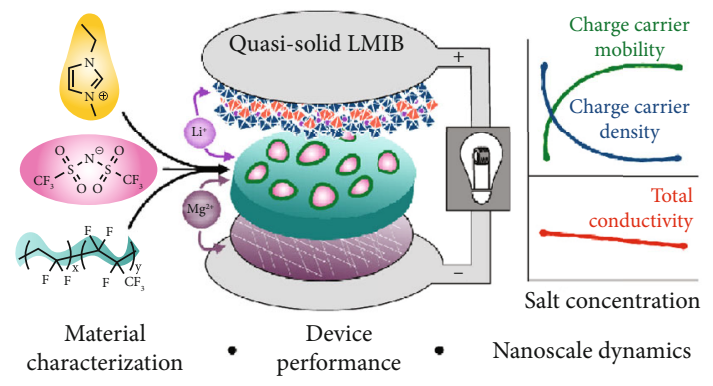

(e)

Figure 5: (a) Cycling performance comparison of symmetric Li/Li cells and $\mathrm{Mg} / \mathrm{Mg}$ cells in dual-salt electrolyte at 20 C [47]. (b) CE of $\mathrm{Mg} / \mathrm{Cu}$ cell in LBhfip/DME electrolyte cycled at $0.5 \mathrm{~mA} \mathrm{~cm}^{-2}$. (c) $\mathrm{Li} 1 \mathrm{~s}$ XPS spectrum for cycled $\mathrm{Mg}$ anode surface from $\mathrm{Mg} / \mathrm{Cu}$ cell in LBhfip/DME electrolyte after 100 charge-discharge cycles [63]. (d) Cycling behavior of $\mathrm{Mg} / \mathrm{Mg}$ symmetrical cells in pristine $[\mathrm{Mg} \cdot 6 \mathrm{THF}]\left[\mathrm{AlCl}_{4}\right]_{2}$ (blue) and $\mathrm{LiCl}$-added (red) electrolytes at the current densities from 10 to $500 \mu \mathrm{A} \mathrm{cm}{ }^{-2}$ [14]. (e) Configuration of quasi-solid-state Li-Mg dual-salt battery and the relationship between salt concentration and charge carrier mobility and density [64].

surface of $\mathrm{Mg}$ anode. Inorganic $\mathrm{Li}$ salts including $\mathrm{Li}_{2} \mathrm{CO}_{3}$, $\mathrm{Li}_{2} \mathrm{O}$, and $\mathrm{LiF}$ species are detected on the cycled $\mathrm{Mg}$ electrode surface (Figure 5(c)). The SEI formed in LBhfip/DME electrolyte is more uniform and denser than that in MBhfip/DME. It is one of the potential reasons that Li-containing SEI can resist the passivation of $\mathrm{Mg}$ metal electrode in conventional electrolytes.

Adding an appropriate amount of LiTFSI to the $\mathrm{Mg}(\mathrm{TFSI})_{2} /$ diglyme electrolyte can enhance the Mg plating/stripping performance with improved CE and significantly decreased overpotential [31]. Recently, the $\mathrm{LiCl}$ additive was also found to enable the reduction of overpotential of $\mathrm{Mg}$ deposition/dissolution in the MACC electrolyte. Fan et al. activated the $\mathrm{Mg}$ anode/electrolyte interface through the solubilization effect of $\mathrm{LiCl}$ on $\mathrm{MgCl}_{2}$, thereby obtaining an $\mathrm{Mg} / \mathrm{S}$ battery with an extended cycle life [14]. The lowsolubility $\mathrm{MgCl}_{2}$ on the $\mathrm{Mg}$ surface may cause high-voltage polarization. By adding $1 \mathrm{M} \mathrm{LiCl}$, the solubility of $\mathrm{MgCl}_{2}$ in THF can be increased to $0.6 \mathrm{M}$. As seen in Figure 5(d), the $\mathrm{Mg} / \mathrm{Mg}$ symmetric cell using $\mathrm{LiCl}$-added electrolyte shows the almost constant overpotential, while the overpotential in pristine MACC electrolyte increases sharply as the current density increases from 10 to $500 \mu \mathrm{A} \mathrm{cm}^{-2}$. Notably, the decrease of overpotential is the synergistic effect of $\mathrm{Li}^{+}$and $\mathrm{Cl}^{-}$, as well as the possible formation of soluble intermediate $\left[\mathrm{Mg}_{2}(\mu-\mathrm{Cl})_{3} \cdot 6 \mathrm{THF}\right]\left[\mathrm{LiCl}_{2} \cdot 2 \mathrm{THF}\right]$, while neither $\mathrm{Li}^{+}$(from LiTFSI) nor $\mathrm{Cl}^{-}$(from $\mathrm{NaCl}$ ) alone can achieve a similar effect as $\mathrm{LiCl}$.
Since many Mg-Li hybrid electrolytes contain $\mathrm{Cl}^{-}$, the corrosion issue in liquid electrolytes cannot be avoided. Therefore, the fabrication of solid electrolyte free of $\mathrm{Cl}$ is a good strategy to remove this obstacle. Recently, Herzog-Arbeitman et al. first proposed the concept of quasi-solid-state $\mathrm{Mg}$-Li hybrid battery (Figure 5(e)) with a high initial capacity of $141.5 \mathrm{~mA} \mathrm{hg}^{-1}$ (based on $\mathrm{LiFePO}_{4}$ cathode) and CE over $90 \%$ in a Swagelok cell configuration [64]. The novel hybrid gel polymer electrolyte was prepared by swelling a poly(vinylidene difluoride-co-hexafluoropropylene) polymer matrix in 1-ethyl-2-methyl imidazolium bis(trifluoromethylsulfonyl)imide (EMITFSI) ionic liquid containing the salts LiTFSI and $\mathrm{Mg}(\mathrm{TFSI})_{2}$. With the salt concentration increasing, the ionic mobility increases but the carrier number density decreases; thus, there are the optimum salt concentrations of $0.7 \mathrm{M}$ LiTFSI and $0.7 \mathrm{M} \mathrm{Mg}(\mathrm{TFSI})_{2}$ with an ionic conductivity of 3.2 $\mathrm{mS} \mathrm{cm}^{-1}$. Although there is a fatal decay of this quasisolid-state battery in the later cycles $(<100$ cycles), the first step has been taken in the development of a noncorrosive and processable electrolyte for $\mathrm{Mg}$-Li hybrid solid-state batteries.

\section{Conclusion}

This review has summarized the recent progresses in $\mathrm{Mg}-\mathrm{Li}$ hybrid batteries as a promising, high-energy-density, and cost-efficient alternative to Li-based systems. Among the 


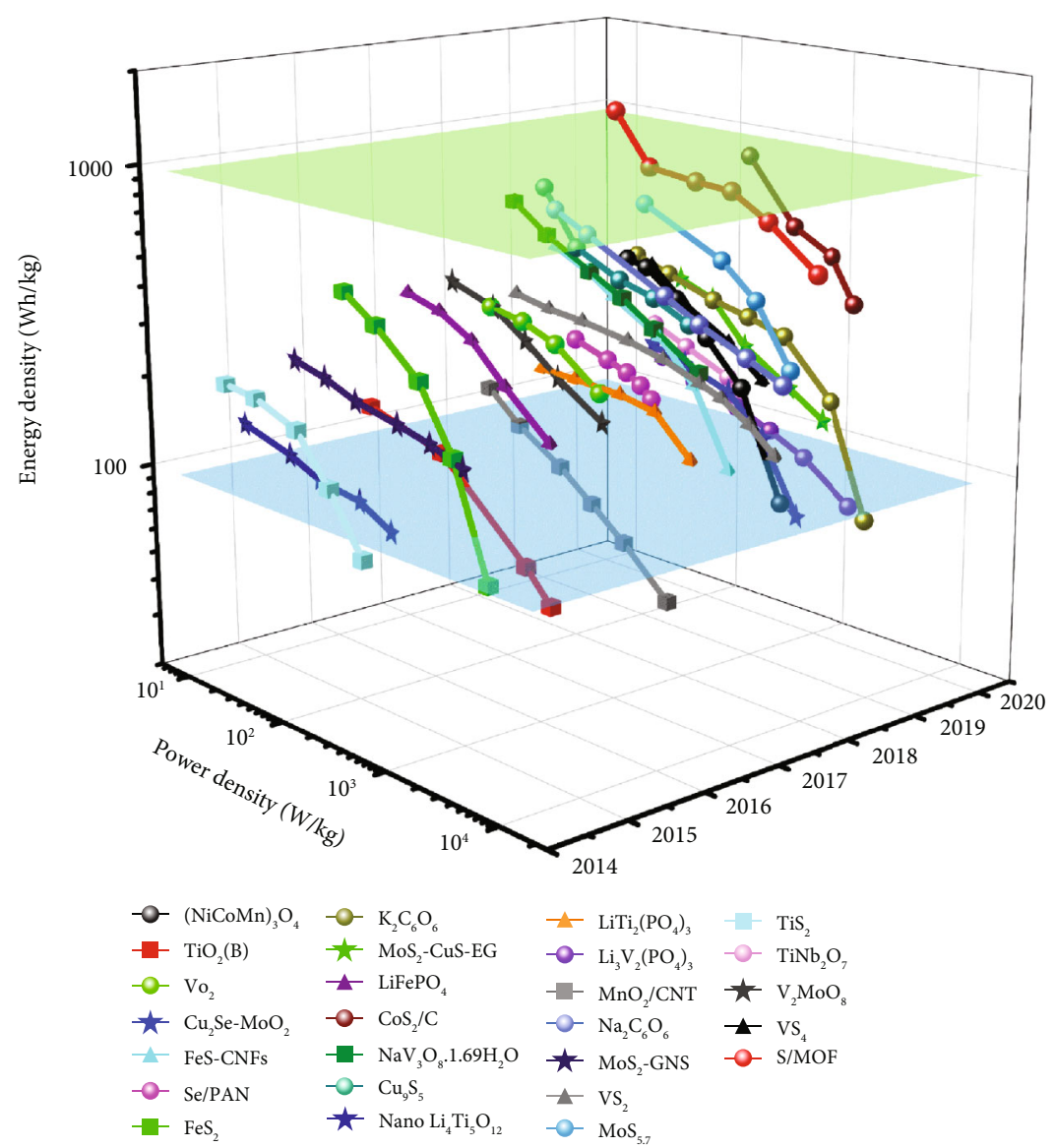

(a)

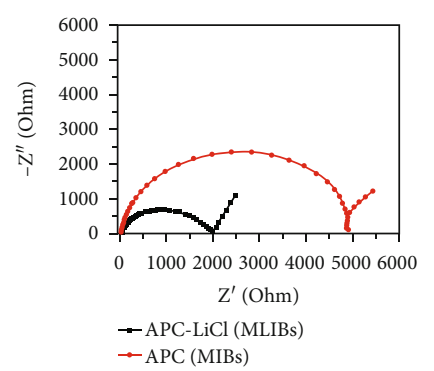

The reduced charge transfer resistance and enhanced kinetics

(b)

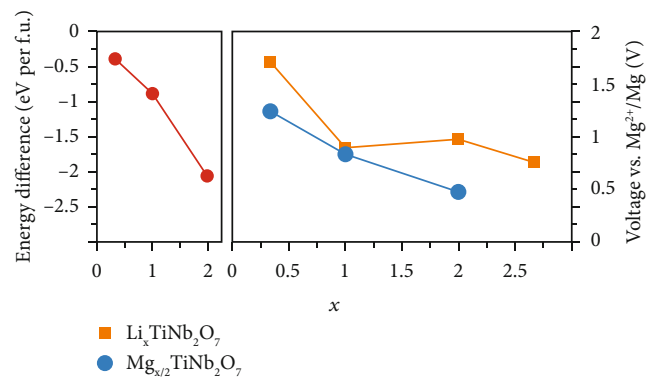

(c)

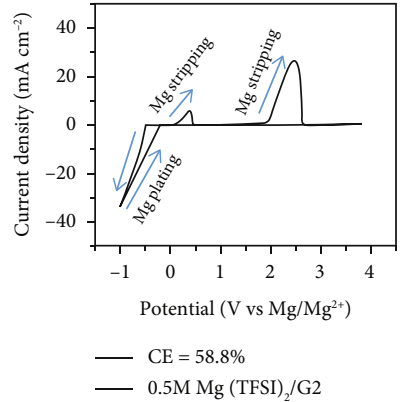

(d)

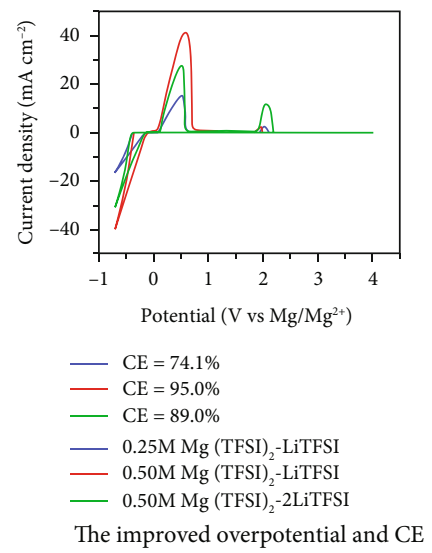

(e)

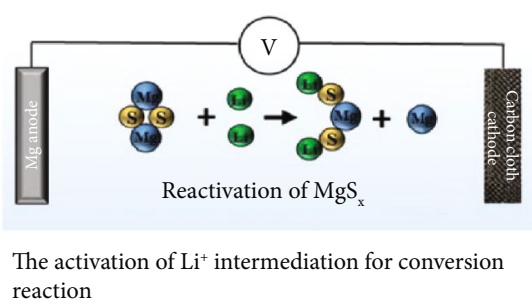

(f)

Figure 6: (a) Comparison of energy density and power density of some dual-salt systems mentioned in this review. (b) Electrochemical impedance spectra of $\mathrm{VS}_{4}$ nanodendrites in Mg battery configurations without and with Li salt additive [22]. (c) Left: energy difference between the intercalation of $\mathrm{x} \mathrm{Li}$ atoms and the corresponding intercalation of $\mathrm{x} / 2 \mathrm{Mg}$ atoms; right: the voltage plots as a function of cation insertion amount of $\mathrm{x} \mathrm{Li}$ or $\mathrm{x} / 2 \mathrm{Mg}$ into TNO [47]. Cyclic voltammogram curves of (d) $0.5 \mathrm{M} \mathrm{Mg}(\mathrm{TFSI})_{2}$ in diglyme (G2) and (e) $\mathrm{Mg}(\mathrm{TFSI})_{2}-\mathrm{Li}(\mathrm{TFSI})_{2} / \mathrm{G} 2$ with different salt concentrations at $100 \mathrm{mV} \mathrm{s}^{-1}$ (platinum as working electrode and polished magnesium ribbons as counter and reference electrodes) [31]. (f) Schematic diagram of $\mathrm{Li}^{+}$mediation in activating $\mathrm{MgS}_{\mathrm{x}}$ species [12].

alternatives to LIBs, most multivalent metal batteries still suffer sluggish kinetics. Mg-Li hybrid batteries combine the advantages of both Li ion and $\mathrm{Mg}$ metal, including fast ion transport kinetics and smooth anode deposition. Research into Mg-Li hybrid batteries has been more widespread in the last several years, and especially recently, it has a trend of revival. We select some typical examples mentioned in this review and compared their energy density and power density in Figure 6. It is found that the conversion-type and multi-electron transfer cathodes (e.g., sulfur, sulfides, organics, and $\mathrm{NaV}_{3} \mathrm{O}_{8}$ ) have the higher energy density $\left(>400 \mathrm{Wh} \mathrm{kg}^{-1}\right)$ than that of insertion-type or singleelectron transfer cathodes. The Mg-Li hybrid systems have shown promise to become a new energy storage system in the post-lithium-ion batteries era, though the above data ignores the weight of battery components. Compared with pure $\mathrm{Mg}$ electrolyte, the advantages of Mg-Li dual-salt electrolyte are also summarized in Figure 6. The presence of $\mathrm{Li}^{+}$with excellent kinetics is beneficial to reduce the interface resistance. From the energy point of view, $\mathrm{Li}^{+}$is preferably 
inserted into cathode host. And the improvement of overpotential and CE by Li salts is also worth noting. In addition, $\mathrm{Li}^{+}$can reactivate the conversion reaction products (e.g., $\mathrm{MgS}_{x}$ ) to improve the electrochemical reversibility of conversion type $\mathrm{Mg}$-based batteries. Some other highlights are listed below.

(1) In the majority of the hybrid battery systems mentioned in this review, the used electrolyte is a combination of APC and $\mathrm{LiCl}$. And the concentration of $\mathrm{LiCl}$ has an effect on the conductivity and viscosity of the electrolyte, as well as the capacity $[28,32,39]$. At present, the combination of $0.25 \mathrm{M} \mathrm{APC}$ and $1 \mathrm{M} \mathrm{LiCl}$ is more applied in the investigation of $\mathrm{Mg}$-Li hybrid system. In addition, the side reaction between APC and the current collector will narrow the actual electrochemical window [41]

(2) Another important factor to influence the overall battery performance is the morphology and size of cathode grains. Hollow and porous structures can facilitate electrolyte infiltration and accommodate volume expansion during cycling $[17,30,38]$. Several research results discussed in this review confirmed that the nanosized cathode materials deliver a higher capacity than the corresponding microsized ones [26, 27]. This may be due to the large surface area and the enhanced mass transfer between electrolyte and active material

(3) For the systems containing APC, it is necessary to use Mo current collector (or stainless steel with coating) to design the high voltage Mg-Li hybrid batteries [11, 28]. Considering the possible commercialization of $\mathrm{Mg}$-Li hybrid batteries in the future, cathode fabrication process and selection of current collector should be taken seriously. The cost factor cannot be ignored; thus, cheap and earth-abundant elements (e.g., Fe, S, and organics) are preferred

(4) For the intercalation-type cathodes, there are two intercalation mechanisms, including exclusive $\mathrm{Li}^{+}$ intercalation and $\mathrm{Mg}^{2+} / \mathrm{Li}^{+}$cointercalation. For the cathodes with $\mathrm{Mg}^{2+} / \mathrm{Li}^{+}$cointercalation, only $\mathrm{VS}_{4}$ and prelithiated $\mathrm{V}_{2} \mathrm{C}$ show that $\mathrm{Mg}^{2+}$ contributes more capacity than $\mathrm{Li}^{+}$and nanosized LTO shows an almost equal contribution of $\mathrm{Mg}^{2+}$ to that of $\mathrm{Li}^{+}[22,26,45]$. The insertion of $\mathrm{Mg}^{2+}$ is more likely to cause irreversible phase transition and even structural collapse, leading to rapid capacity fading [48]. Therefore, whether to design a cathode that allows sufficient $\mathrm{Mg}^{2+}$ insertion still needs to be carefully considered

(5) For Mg metal anode, the addition of Li salts significantly reduces the overpotential of $\mathrm{Mg}$ plating/stripping and constructs a reinforced SEI in noncorrosive electrolyte (e.g., LBhifp/DME) [14, 31, 63]. The improvement of electrochemical performance at $\mathrm{Mg}$ anode side may attribute to the reduced interfacial resistance and the enhanced interfacial compatibility

\section{Prospect}

In theory, Mg-Li hybrid battery is a good candidate for highperformance batteries, but in terms of practical energy densities, LIBs are still better. LIBs have achieved commercialization for several decades. And after a considerable amount of research, their energy density is almost close to the bottleneck. Even with the intensified efforts since 2014, the research into Mg-Li hybrid batteries is in its infancy. The significant investigations are still required to realize their practical applications.

To achieve high theoretical values in Mg-Li hybrid battery configuration, electrolyte must have high ion conductivity and wide electrochemical window. Although some $\mathrm{Mg}$ electrolytes have been developed over the years, they cannot replace APC in terms of cost, synthesis process, and compatibility with $\mathrm{Mg}$ metal anode. Thus, developing stable and practical electrolyte and $\mathrm{Mg}$ metal anode are necessary. The cathode must be well designed, such as constructing hierarchical porous structure to make electrolyte permeate cathode material, alleviate its volume expansion, and improve the diffusion kinetics. To enhance the electrical conductivity of cathode, sufficient electronic conductive network or wiring is also essential. As a research hotspot, fast charging is also a future trend. Therefore, it is also necessary to improve the rate performance of the $\mathrm{Mg}$-Li hybrid system to reach practical level. In addition, for $S$ cathode, there is also a severe shuttle effect, and more modification strategies are required, such as separator decoration and charging mode optimization. The research on the influence of dual-salt electrolyte on the anode is far from enough, including but not limited to the composition of SEI and the effect of Li salt on the solvation structure, which need more in-depth analysis. In terms of practicality, some issues about electrolyte must be investigated in depth. Most the reports of Mg-Li hybrid batteries adopted glass fiber as the separator based on a coin cell configuration. It is inevitable that more amount of electrolyte is required to wet the inner separator compared with the case of commercial polymer Celgard as the separator. Combining with the active material mass loading, the volume of electrolyte with extra $\mathrm{Li}$ salt consumption used in Mg-Li hybrid systems is still far from the lean electrolyte standard of MMBs. Thus, more investigations under practical conditions (e.g., high mass loading, highconcentration salt, and pouch cell configuration) are urgently needed.

\section{Data Availability}

All data related to the analysis in this study are present in the paper.

\section{Conflicts of Interest}

The authors declare no conflict of interest. 


\section{Authors' Contributions}

YJL and CLL analyzed the data and wrote and revised the manuscript. YJL and YJZ prepared the figures. CLL, KG, and JTZ supervised the project.

\section{Acknowledgments}

This work was supported by the National Key R\&D Program of China (2016YFB0901600), NSAF (Grant No. U1830113), the National Natural Science Foundation of China (51772313 and 21975276), and Shanghai Science and Technology Committee (20520710800).

\section{References}

[1] J. W. Choi and D. Aurbach, "Promise and reality of postlithium-ion batteries with high energy densities," Nature Reviews Materials, vol. 1, no. 4, article 16013, 2016.

[2] R. Attias, M. Salama, B. Hirsch, Y. Goffer, and D. Aurbach, "Anode-electrolyte interfaces in secondary magnesium batteries," Joule, vol. 3, no. 1, pp. 27-52, 2019.

[3] D. Aurbach, Z. Lu, A. Schechter et al., "Prototype systems for rechargeable magnesium batteries," Nature, vol. 407, no. 6805, pp. 724-727, 2000.

[4] S. Yagi, T. Ichitsubo, Y. Shirai et al., "A concept of dual-salt polyvalent-metal storage battery," Journal of Materials Chemistry A, vol. 2, no. 4, pp. 1144-1149, 2014.

[5] T. Ichitsubo, S. Okamoto, T. Kawaguchi et al., "Toward "rocking-chair type" Mg-Li dual-salt batteries," Journal of Materials Chemistry A, vol. 3, no. 19, pp. 10188-10194, 2015.

[6] Y. Gofer, O. Chusid, H. Gizbar et al., "Improved electrolyte solutions for rechargeable magnesium batteries," Electrochemical and Solid State Letters, vol. 9, no. 5, pp. A257-A260, 2006.

[7] Y. Cheng, Y. Shao, J.-G. Zhang, V. L. Sprenkle, J. Liu, and G. Li, "High performance batteries based on hybrid magnesium and lithium chemistry," Chemical Communications, vol. 50, no. 68, pp. 9644-9646, 2014.

[8] J.-H. Cho, M. Aykol, S. Kim et al., "Controlling the intercalation chemistry to design high-performance dual-salt hybrid rechargeable batteries," Journal of the American Chemical Society, vol. 136, no. 46, pp. 16116-16119, 2014.

[9] R. Mohtadi, M. Matsui, T. S. Arthur, and S.-J. Hwang, "Magnesium borohydride: from hydrogen storage to magnesium battery," Angewandte Chemie-International Edition, vol. 51, no. 39, pp. 9780-9783, 2012.

[10] Y. Shao, T. Liu, G. Li et al., "Coordination chemistry in magnesium battery electrolytes: how ligands affect their performance," Scientific Reports, vol. 3, article 3130, 2013.

[11] Y. Cheng, D. Choi, K. S. Han et al., "Toward the design of high voltage magnesium-lithium hybrid batteries using dual-salt electrolytes," Chemical Communications, vol. 52, no. 31, pp. 5379-5382, 2016.

[12] T. Gao, M. Noked, A. J. Pearse et al., "Enhancing the reversibility of $\mathrm{Mg} / \mathrm{S}$ battery chemistry through $\mathrm{Li}^{+}$mediation," Journal of the American Chemical Society, vol. 137, no. 38, pp. 1238812393, 2015.

[13] Y. Yang, W. Wang, Y. Nuli, J. Yang, and J. Wang, "High active magnesium trifluoromethanesulfonate-based electrolytes for magnesium-sulfur batteries," ACS Applied Materials \& Interfaces, vol. 11, no. 9, pp. 9062-9072, 2019.
[14] H. Fan, Z. Zheng, L. Zhao et al., "Extending cycle life of $\mathrm{Mg} / \mathrm{S}$ battery by activation of $\mathrm{mg}$ anode/electrolyte interface through an $\mathrm{LiCl}$-assisted $\mathrm{MgCl}_{2}$ solubilization mechanism," Advanced Functional Materials, vol. 30, no. 9, article 1909370, 2020.

[15] C.-J. Hsu, C.-Y. Chou, C.-H. Yang, T.-C. Lee, and J.-K. Chang, " $\mathrm{MoS}_{2}$ /graphene cathodes for reversibly storing Mg2+and $\mathrm{Mg} 2+/ \mathrm{Li}+$ in rechargeable magnesium-anode batteries," Chemical Communications, vol. 52, no. 8, pp. 1701-1704, 2016.

[16] L. Wang, Z. Xu, W. Wang, and X. Bai, "Atomic mechanism of dynamic electrochemical lithiation processes of MoS2Nanosheets," Journal of the American Chemical Society, vol. 136, no. 18, pp. 6693-6697, 2014.

[17] X. Hou, H. Shi, T. Chang et al., "Hollow opening nanoflowers $\mathrm{MoS}_{2}$-CuS-EG cathodes for high-performance hybrid $\mathrm{Mg} / \mathrm{Li}$ ion batteries," Chemical Engineering Journal, vol. 409, article 128271, 2020.

[18] T. Gao, F. Han, Y. Zhu et al., "Hybrid $\mathrm{Mg}^{2+} / \mathrm{Li}^{+}$battery with long cycle life and high rate capability," Advanced Energy Materials, vol. 5, no. 5, article 1401507, 2015.

[19] H. D. Yoo, Y. Liang, Y. Li, and Y. Yao, "High areal capacity hybrid magnesium-lithium-ion battery with $99.9 \%$ coulombic efficiency for large-scale energy storage," ACS Applied Materials \& Interfaces, vol. 7, no. 12, pp. 7001-7007, 2015.

[20] R. Sun, C. Pei, J. Sheng et al., "High-rate and long-life $\mathrm{VS}_{2}$ cathodes for hybrid magnesium-based battery," Energy Storage Materials, vol. 12, pp. 61-68, 2018.

[21] Y. Wang, Z. Liu, C. Wang et al., "Highly branched VS4Nanodendrites with $1 \mathrm{D}$ atomic-chain structure as a promising cathode material for long-cycling magnesium batteries," Advanced Materials, vol. 30, no. 32, article 1802563, 2018.

[22] Y. Wang, C. Wang, X. Yi et al., "Hybrid Mg/Li-ion batteries enabled by $\mathrm{Mg}^{2+} / \mathrm{Li}^{+}$co-intercalation in $\mathrm{VS}_{4}$ nanodendrites," Energy Storage Materials, vol. 23, pp. 741-748, 2019.

[23] Z. Chen, I. Belharouak, Y. K. Sun, and K. Amine, “Titaniumbased anode materials for safe lithium-ion batteries," Advanced Functional Materials, vol. 23, no. 8, pp. 959-969, 2013.

[24] S. Su, Z. Huang, Y. Nu Li, F. Tuerxun, J. Yang, and J. Wang, "A novel rechargeable battery with a magnesium anode, a titanium dioxide cathode, and a magnesium borohydride/tetraglyme electrolyte," Chemical Communications, vol. 51, no. 13, pp. 2641-2644, 2015.

[25] N. Wu, Y. C. Lyu, R. J. Xiao et al., "A highly reversible, lowstrain $\mathrm{Mg}$-ion insertion anode material for rechargeable $\mathrm{Mg}$ ion batteries," npg Asia Materials, vol. 6, no. 8, article e120, 2014.

[26] N. Wu, Z. Z. Yang, H. R. Yao, Y. X. Yin, L. Gu, and Y. G. Guo, "Improving the electrochemical performance of the Li4Ti5O12Electrode in a rechargeable magnesium battery by lithium-magnesium co-intercalation," Angewandte ChemieInternational Edition, vol. 54, no. 19, pp. 5757-5761, 2015.

[27] Q. Miao, Y. Nu Li, N. Wang, J. Yang, J. Wang, and S. I. Hirano, "Effect of $\mathrm{Mg} 2+/ \mathrm{Li}+$ mixed electrolytes on a rechargeable hybrid battery with Li4Ti5O12cathode and Mg anode," RSC Advances, vol. 6, no. 4, pp. 3231-3234, 2016.

[28] Y. Yao, L. Zhang, X. Bie et al., "Exploration of spinel LiCrTiO4as cathode material for rechargeable $\mathrm{Mg}$-Li hybrid batteries," Chemistry A European Journal, vol. 23, no. 71, pp. 17935-17939, 2017. 
[29] M. Asif, M. Rashad, Z. Ali et al., "Ni-doped $\mathrm{MnO}_{2} / \mathrm{CNT}$ nanoarchitectures as a cathode material for ultra-long life magnesium/lithium hybrid ion batteries," Materials Today Energy, vol. 10, pp. 108-117, 2018.

[30] M. Asif, M. Rashad, Z. Ali, and I. Ahmed, "Synthesis of ternary metal oxides as positive electrodes for Mg-Li hybrid ion batteries," Nanoscale, vol. 12, no. 2, pp. 924-932, 2020.

[31] B. Pan, Z. Feng, N. Sa et al., "Advanced hybrid battery with a magnesium metal anode and a spinel LiMn2O4cathode," Chemical Communications, vol. 52, no. 64, pp. 9961-9964, 2016.

[32] Y. Cen, Y. Liu, Y. Zhou et al., "Spinel Li4Mn5O12as $2.0 \mathrm{~V}$ insertion materials for Mg-based hybrid ion batteries," ChemElectroChem, vol. 7, no. 5, pp. 1115-1124, 2020.

[33] C. Pei, F. Xiong, J. Sheng et al., " $\mathrm{VO}_{2}$ nanoflakes as the cathode material of hybrid magnesium-lithium-ion batteries with high energy density," ACS Applied Materials \& Interfaces, vol. 9, no. 20, pp. 17061-17067, 2017.

[34] Y. Yue and H. Liang, "Micro- and nano-structured vanadium pentoxide $\left(\mathrm{V}_{2} \mathrm{O}_{5}\right)$ for electrodes of lithium-ion batteries," Advanced Energy Materials, vol. 7, no. 17, article 1602545, 2017.

[35] H. D. Yoo, I. Shterenberg, Y. Gofer, G. Gershinsky, N. Pour, and D. Aurbach, "Mg rechargeable batteries: an on-going challenge," Energy \& Environmental Science, vol. 6, no. 8, pp. 2265-2279, 2013.

[36] X. Miao, Z. Chen, N. Wang et al., "Electrospun $\mathrm{V}_{2} \mathrm{MoO}_{8}$ as a cathode material for rechargeable batteries with mg metal anode," Nano Energy, vol. 34, pp. 26-35, 2017.

[37] M. Rashad, X. Li, and H. Zhang, "Magnesium/lithium-ion hybrid battery with high reversibility by employing $\mathrm{NaV}_{3} \mathrm{O}_{8} \cdot 1.69 \mathrm{H}_{2} \mathrm{O}$ nanobelts as a positive electrode," ACS Applied Materials \& Interfaces, vol. 10, no. 25, pp. 2131321320, 2018.

[38] W. Pan, X. Liu, X. Miao et al., "Molybdenum dioxide hollow microspheres for cathode material in rechargeable hybrid battery using magnesium anode," Journal of Solid State Electrochemistry, vol. 19, no. 11, pp. 3347-3353, 2015.

[39] Y. Xu, C. Xu, Q. An et al., "Robust LiTi2(PO4)3microflowers as high-rate and long-life cathodes for Mg-based hybrid-ion batteries," Journal of Materials Chemistry A, vol. 5, no. 27, pp. 13950-13956, 2017.

[40] X. Sun, V. Duffort, and L. F. Nazar, "Prussian blue Mg-Li hybrid batteries," Advanced Science, vol. 3, no. 8, article 1600044, 2016.

[41] Z. Zhang, H. Xu, Z. Cui et al., "High energy density hybrid $\mathrm{Mg} 2+/ \mathrm{Li}+$ battery with superior ultra-low temperature performance," Journal of Materials Chemistry A, vol. 4, no. 6, pp. 2277-2285, 2016.

[42] M. Rashad, H. Zhang, X. Li, and H. Zhang, "Fast kinetics of $\mathrm{Mg} 2+/ \mathrm{Li}+$ hybrid ions in a polyanion Li3V2(PO4)3cathode in a wide temperature range," Journal of Materials Chemistry A, vol. 7, no. 16, pp. 9968-9976, 2019.

[43] S. Fleischmann, J. B. Mitchell, R. Wang et al., "Pseudocapacitance: from fundamental understanding to high power energy storage materials," Chemical Reviews, vol. 120, no. 14, pp. 6738-6782, 2020.

[44] S. Su, Y. Nuli, Z. Huang, Q. Miao, J. Yang, and J. Wang, “A high-performance rechargeable $\mathrm{Mg} 2+/ \mathrm{Li}+$ Hybrid battery using one-dimensional mesoporous $\mathrm{TiO}_{2}(\mathrm{~B})$ nanoflakes as the cathode," ACS Applied Materials \& Interfaces, vol. 8, no. 11, pp. 7111-7117, 2016.
[45] F. Liu, Y. Liu, X. Zhao, K. Liu, H. Yin, and L. Z. Fan, "Prelithiated $\mathrm{V}_{2} \mathrm{C}$ Mxene: a high-performance electrode for hybrid magnesium/lithium-ion batteries by ion cointercalation," Small, vol. 16, no. 8, article 1906076, 2020.

[46] S. Maletti, A. Herzog-Arbeitman, S. Oswald, A. Senyshyn, L. Giebeler, and D. Mikhailova, "TiNb2O7and VNb9O25of ReO3Type in hybrid Mg-Li batteries: electrochemical and interfacial insights," Journal of Physical Chemistry C, vol. 124, no. 46, pp. 25239-25248, 2020.

[47] S. Maletti, O. Janson, A. Herzog-Arbeitman et al., "Operation mechanism in hybrid Mg-Li batteries with TiNb2O7Allowing stable high-rate cycling," ACS Applied Materials \& Interfaces, vol. 13, no. 5, pp. 6309-6321, 2021.

[48] J. Tian, D. Cao, X. Zhou, J. Hu, M. Huang, and C. Li, "Highcapacity Mg-organic batteries based on nanostructured rhodizonate salts activated by $\mathrm{Mg}-\mathrm{Li}$ dual-salt electrolyte," ACS Nano, vol. 12, no. 4, pp. 3424-3435, 2018.

[49] J. Tian, X. Zhou, Q. Wu, and C. Li, "Li-salt mediated Mgrhodizonate batteries based on ultra-large cathode grains enabled by K-ion pillaring," Energy Storage Materials, vol. 22, pp. 218-227, 2019.

[50] Y. Zhang, J. Xie, Y. Han, and C. Li, "Dual-salt Mg-based batteries with conversion cathodes," Advanced Functional Materials, vol. 25, no. 47, pp. 7300-7308, 2015.

[51] X. Chen, S. Wang, and H. Wang, "High performance hybrid $\mathrm{Mg}$-Li ion batteries with conversion cathodes for low cost energy storage," Electrochimica Acta, vol. 265, pp. 175-183, 2018.

[52] T. Li, A. Qin, H. Wang et al., "A high-performance hybrid $\mathrm{Mg}^{2+} / \mathrm{Li}^{+}$battery based on hierarchical copper sulfide microflowers conversion cathode," Electrochimica Acta, vol. 263, pp. $168-175,2018$.

[53] C. Wu, J. Hu, J. Tian et al., "Stacking of tailored chalcogenide nanosheets around $\mathrm{MoO}_{2}-\mathrm{C}$ conductive stakes modulated by a hybrid $\mathrm{POM} \subset \mathrm{MOF}$ precursor template: composite conversion-insertion cathodes for rechargeable $\mathrm{Mg}$ - Li dualsalt batteries," ACS Applied Materials \& Interfaces, vol. 11, no. 6, pp. 5966-5977, 2019.

[54] W. Wang, Y. Yang, Y. Nu Li, J. Zhou, J. Yang, and J. Wang, "Metal organic framework (MOF)-derived carbonencapsulated cuprous sulfide cathode based on displacement reaction for hybrid $\mathrm{Mg}^{2+} / \mathrm{Li}^{+}$batteries," Journal of Power Sources, vol. 445, article 227325, 2020.

[55] M. Asif, M. Rashad, and Z. Ali, "Electrochemical intercalations of divalent ions inside $\mathrm{Ni} / \mathrm{Zn}$ co-doped cobalt sulfide nanoparticle decorated carbon spheres with superior capacity," Nanoscale, vol. 12, no. 26, pp. 14267-14278, 2020.

[56] C. Liu, G. Zhao, L. Zhang et al., "A hybrid $\mathrm{Mg}^{2+} / \mathrm{Li}^{+}$battery based on high-capacity conversion-type cobalt disulfide cathodes with ultralong cycle life and high energy density," Chemical Engineering Journal, vol. 405, article 126726, 2021.

[57] J. Zhu, Y. Liu, T. Mu et al., " $\mathrm{NiSe}_{2} / \mathrm{Ti}_{3} \mathrm{C}_{2}$ as a promising cathode material for rechargeable dual $\mathrm{Mg} / \mathrm{Li}$-ion battery," Materials Letters, vol. 283, article 128721, 2021.

[58] H. S. Kim, T. S. Arthur, G. D. Allred et al., "Structure and compatibility of a magnesium electrolyte with a sulphur cathode," Nature Communications, vol. 2, no. 1, 2011.

[59] Z. Zhao-Karger, X. Zhao, D. Wang, T. Diemant, R. J. Behm, and M. Fichtner, "Performance improvement of magnesium sulfur batteries with modified non-nucleophilic electrolytes," Advanced Energy Materials, vol. 5, no. 3, article 1401155, 2015. 
[60] X. Zhou, J. Tian, J. Hu, and C. Li, "High rate magnesium-sulfur battery with improved cyclability based on metal-organic framework derivative carbon host," Advanced Materials, vol. 30, no. 7, article 1704166, 2018.

[61] X. Wang, J. Ding, J. Chen, and M. Xue, "Improved $\mathrm{Li}^{+}$diffusion enabled by SEI film in a high- energy-density hybrid magnesium-ion battery," Journal of Power Sources, vol. 441, article 227190, 2019.

[62] H. Yuan, Y. Yang, Y. Nu Li, J. Yang, and J. Wang, "A conductive selenized polyacrylonitrile cathode in nucleophilic $\mathrm{Mg} 2+/ \mathrm{Li}+$ hybrid electrolytes for magnesium-selenium batteries," Journal of Materials Chemistry A, vol. 6, no. 35, pp. 17075-17085, 2018.

[63] K. Tang, A. Du, S. Dong et al., "A stable solid electrolyte interphase for magnesium metal anode evolved from a bulky anion lithium salt," Advanced Materials, vol. 32, no. 6, article 1904987, 2020.

[64] A. Herzog-Arbeitman, S. Maletti, S. Oswald, T. Schmeida, L. Giebeler, and D. Mikhailova, "A highly conductive gel polymer electrolyte for Li-Mg hybrid batteries," ACS Applied Energy Materials, vol. 4, no. 2, pp. 1906-1914, 2021. 